\title{
SIMMEL Y LA CULTURA DEL CONSUMO
}

\author{
José Miguel Marinas
}

Universidad Complutense de Madrid

\begin{abstract}
RESUMEN
Este artículo, que se encuadra en una serie de trabajos sobre los orígenes de la cultura del consumo en el principio de siglo, presenta un recorrido por los textos simmeliamos relativos a la constitución de la identidad social basada no en el paradigma de la producción, sino en la relación con los objetos y procesos del consumo. Antes de la pauta del consumo de masas surge y se generaliza un modo cultural basado en el lujo y su ostentación (consumo conspicuo, según Veblen) y, en general, de la mediación de las mercancías y su lógica (fetichismo) como formadoras de los sujetos sociales. Los elementos críticos y creativos que Simmel elabora resultarán de una enorme fecundidad en autores como Kracauer y, sobre todo, Walter Benjamin. De esta herencia en el análisis de las metrópolis de los pasajes comerciales (Passagen Werk) se da cuenta detallada en la segunda parte de este trabajo.
\end{abstract}

Simmel sabe más de la sociedad de consumo por berlinés que por sociólogo. Al menos ésa es la primera caracterización de sus comentaristas actuales. La sociedad en la que vive se encuentra en el momento de transición, rico en tensiones latentes, entre una industrialización consolidada y los efectos no previstos de la misma. Entre un sistema de pautas productivas que ahorma la vida y un repertorio de identidades cambiantes cada vez más volcadas del lado de los objetos, los signos, el universo del consumo. Como entre dos calles berlinesas, Simmel vive entre el capitalismo de producción, triunfante en apariencia, y las primeras crisis de éste, que se intentan paliar o sustanciar

\section{Reis}


en la otra escena: la del tiempo quebrado, plural y espectacular del consumo incipiente.

Como Veblen acuñó para su final de siglo, el modelo de sociedad con el que Simmel se enfrenta es el del consumo conspicuo. Una sociedad en la que la acumulación dineraria de la industrialización engendra una nueva clase ociosa. Y, sobre todo, propone un nuevo modelo de socialización: la pauta de consumo elitista que se da como espectáculo a la emulación de las nuevas capas sociales de trabajadores a los que inquietan y atraen los signos de la nueva riqueza. Pero el impulso de Simmel no cuaja sólo en una mejor modelización de la economía. Como el jefe samoano que retrató su sorpresa ante la Europa de los años veinte en el libro de cartas Los Papalagi ${ }^{1}$, Simmel lleva su extrañeza hasta la indagación de la cultura profunda que genera la moda y el consumo en todos los campos de la vida. Así descubre la fractura de los tiempos y los intentos de sutura que supone el troquelado de las mentalidades por la técnica, la construcción social de la forma mercancía y del dinero, la importancia de la moda (que aprovecha las desigualdades y las domestica), y la posibilidad de la estilización de la vida.

Lo que está cambiando no es sólo un sistema económico y sus reglas. La gran mutación, por debajo incluso de las representaciones conscientes de la ciencia y de la política, toca a la misma esencia del tiempo, a la redefinición de los espacios, a las formas de la identidad. Los personajes sociales del protoconsumo moderno - del consumo aún no generalizado como pauta de masas: esto ocurrirá en la segunda posguerra mundial- participan de la lógica del progreso y del tiempo largo de la historia, pero al mismo tiempo son prisioneros de otro tiempo rompedor y exigente: el instante. Esto no se lo dicen las proclamas, se lo pone en el cuerpo la moda, se lo inculca la rítmica interna de las grandes ciudades, se lo exigen los nuevos objetos de la vida cotidiana. Todos ellos sometidos y sometedores al pasar, al triunfo de lo efímero. La mirada de Simmel es pionera en el análisis de la sociedad de consumo precisamente porque es el primero en plegarse a la vida de las cosas, a lo fugaz que adviene, a los sujetos sociales fabricados por la nueva cultura. Como pronto comprenderán sus seguidores (Lukács, Kracauer, Benjamin) e incluso sus colegas e interlocutores (Weber, Sombart), Simmel es el primero que advierte la llegada de un modo de socialización que redefine la mirada sociológica, pide conceptos nuevos sobre la vida económica e instaura un modelo de análisis de los fenómenos del consumo. Estos pasos más su herencia inmediata - personificada en Benjamin - forman el itinerario que sigue. Así, el recorrido por este gran inventor de miradas y de objetos sociológicos trata de mostrar cómo es su teorización sobre la sociedad de consumo, cuál es la relación con las mercancías ejemplificada en el dinero, cómo es el nuevo tiempo de la moda, qué da de sí su herencia para entender el consumo contemporáneo.

1 Ed. Pastanaga, Barcelona, 1982. 


\section{LA CARA OCULTA DEL CONSUMO Y DE LA SOCIOLOGÍA}

Simmel en su recepción contemporánea va ganando dimensión como teórico del consumo, precisamente en el mismo sentido en que lo hace el propio Marx, en quien se inspira y a quien trata de superar leyéndolo críticamente. Efectivamente, Marx traza el análisis del sistema capitalista partiendo del paradigma de la producción ${ }^{2}$ y, sin embargo, al analizar la esencia misma de la mercancía resultado de este nuevo modo, inicia ya el fundamento crítico de la fase capitalista del consumo. La forma mercancía constituye un modelo estructurante de las relaciones sociales en su conjunto. La dinámica de la producción en este sistema, que cuando Marx hace su crítica está — dice Benjamin- en su infancia, se ve sometida a un nuevo principio objetivador y troquelador de las subjetividades: el que marca el fetichismo de la mercancía, en el que la propiedad y posesión de los bienes desborda la relación individuo-producto para abrirse a la relación estilo de vida-intercambio de bienes. Relación ésta en la que Simmel, sensible a la tarea moral de los individuos, da lo mejor de sí abriendo el campo de la producción al sistema de reglas más amplio que ya incluye el consumo contemporáneo. El sujeto del consumo no es el individuo ${ }^{3}$, sino el entramado de relaciones reales y simbólicas que éste mantiene y que Simmel llama inauguralmente estilo de vida. El objeto del consumo no es el bien que se compra, sino una red mayor de pautas culturales, de relatos y signos en la que los objetos se presentan y adquieren argumento, esto es, sentido.

Por eso se puede decir que Simmel, que ve lo que los demás teóricos no aprecian, traza por primera vez un mapa de la cara oculta del consumo. Y no tanto porque lleve la mirada del lector hacia pasajes escabrosos, sino porque levanta las definiciones de lo evidente para mostrar todo el recorrido de lo que la academia ha acotado y etiquetado. La cara oculta lo es no por azar ni por fatalidad, sino porque la mirada hegemónica no se dirige a ella. La realidad no dicha del mundo del consumo consiste en su globalidad, en el carácter inconsciente de los procesos, en la determinación cultural de las relaciones económicas, en el carácter sociológico de las emociones que bullen en la esfera de lo privado. Éste es el primer cambio de perspectiva que aún sigue suscitando preguntas e interpretaciones. El que lleva a superar la esfera economicista ${ }^{4}$ la del

2 En ese sentido lo encuadra José M.a GonZÁleZ en su «Georg Simmel y Max Weber», en E. LAmo, J. M. GONZÁlez y C. Torres, La sociología del conocimiento y de la ciencia, Madrid, Alianza, 1994, p. 255.

${ }^{3}$ Aunque Simmel señala el gran emergente de la cultura individualista como propia de la sociedad de consumo que se forma en el final de siglo, «individuo» siempre apunta, en su constitución, a una red de relaciones económicas y culturales y, en su tarea social y moral, a una red de vinculaciones en el espacio público. Véase a este respecto el trabajo de Bruno ACCARINO, «Vertrauen und Versprechen. Kredit, Öffentlichkeit un individuelle Entscheidung bei Simmel», en H. DAKME y O. RammstedT, Georg Simmel und die Moderne, Frankfurt am Main, 1984, pp. 116-147.

${ }^{4}$ Sobre la recepción de Simmel en el contexto económico, D. LAIDLER y N. Rowe, «Georg Simmel's Philosophy of Money: A Review Article for Economists», en D. Frisby (ed.), Georg Simmel. Critical Assessments, Londres, Routledge, 1994, vol. II, pp. 264-274. 
psicologismo ${ }^{5}$, es decir, aquellas en las que se hallaban instalados quienes, antes de Simmel, identificaban consumo con compra y consumidor con preferidor racional. Pero esta apreciación que cambia el registro académico no es un fenómeno de ingenio autoproducido.

Es la nueva forma de socialización que circula en las calles de las metrópolis, en sus plazas comerciales y en sus avenidas y pasajes la que cambia la mirada sociológica. La que pide otros conceptos. Los hallazgos simmelianos tienen que ver con las formas de sensibilidad que ya están difundiéndose en los nuevos espacios del consumo, de suerte que es posible mostrar una correspondencia, una afinidad entre éstos y aquélla. Así, si se habla, como ya es tópico, de una sociología impresionista o fragmentaria, lo importante, a mi entender, no es mostrar una moda, sino la capacidad de desplazamiento de una racionalidad académica para salir a la búsqueda e invención de nuevos síntomas. Simmel practica una razón que se atreve a asociar, a derivar persiguiendo las raíces de un fenómeno concreto hasta que éste muestre las más determinaciones posibles. A medio camino entre el impresionismo -como dice Lukács: es un Monet aún no seguido por un Cezanne ${ }^{6}$ - y la posición de flâneur sociológico $^{7}$, Simmel compone diagnósticos con toda suerte de elementos tanto de la vida cotidiana como de los arsenales de la cultura heredada. Su estilo ha sido caracterizado como el de un bricoleur $^{8}$, por la variedad y el carácter constructivista ad hoc de muchos de sus escritos, e incluso de sociología hecha por un extranjero ${ }^{9}$, tremenda metáfora que es el programa de muchos de los mejores analistas de la crisis del cabo de siglo.

«Vivió en la intersección de muchas corrientes conflictivas, intensamente afectado por una multiplicidad de tendencias intelectuales y morales.

5 El debate sobre el Simmel psicologista o — como creo que se puede entender mejorsociólogo de la base formal y social de las emociones y los sentimientos está aclarado en Birgitta Nedelmann, "Psychologism” or Sociology of Emotions? Max Weber's Critique of G.S.'s Sociology», en D. Frisby (ed.), o.c., vol. II, pp. 85-101.

6 Este excelente retrato de G. LUKÁCS, "Georg Simmel», recogido en D. Frisby (ed.), o.c., 1994, vol. I, pp. 98-101, refleja bien la atención de Simmel a lo peculiar en un tiempo «de centro perdido», como el «mayor filósofo de la transición de nuestra época».

7 La expresión lukacsiana da título al célebre trabajo de D. FRISBY, Sociological Impressionism: A reassessment of Georg Simmel's Social Theory, Londres, Heinemann, 1981. El término impresionismo cobra todo su valor, a mi entender, si se pretende, más allá de la metáfora de estilo, centrar los hallazgos de Simmel en un modo de analizar la cultura del que el impresionismo pictórico forma también parte activa.

${ }^{8}$ Así lo nombran Deena y Michel Weinstein, "Georg Simmel: sociological flâneur bricoleur", en D. Frisby (ed.), Georg Simmel. Critical Assessments, Londres, Routledge, 1994, vol. II, pp. 126-139. La plabra flâneur aparece tachada en el título como un pentimento.

9 «Si el desplazarse es la liberación de un punto dado en el espacio, y consiguientemente el concepto opuesto a la fijación en tal punto, la forma sociológica del extranjero presenta una unidad, como tal, de estas dos características.» Así acota Simmel el objeto extranjero y el punto de vista de su sociología «nómada», en K. H. WolfF, The Sociology of Georg Simmel, Free Press of Glencoe, 1964, p. 402. Ver también el significativo artículo de L. Coser, "The Stranger in the Academy», en L. Coser (comp.), Georg Simmel, Nueva Jersey, Prentice Hall, 1965, pp. 37-39. 
Fue un moderno hombre urbano... un extraño en su tierra natal. Como el forastero que describió en uno de sus ensayos más brillantes, estaba cerca y lejos al mismo tiempo, era un "viajero potencial”" ${ }^{10}$.

El que teoriza la extranjería en las grandes áreas y jornadas de la producción, es él mismo un "exótico", en la medida en que toma distancia para con los tópicos y los mapas usuales en el gremio (de los filósofos, de los sociólogos). Va en medio de los nuevos fenómenos quizá no tanto como el flâneur parisino, del que luego veremos algunos matices, sino con la distancia atentísima de Kafka, para quien la ciudad es «jaula y refugio»: «nos paseamos — dice Franz Kafka en su diario- como embutidos en una campana de buzo» ${ }^{11}$. Simmel practica, pues, con los espacios nuevos una sociología no tan impresionista, si por tal entendemos la pérdida de figura, la nueva alegoría que aún no está escrita. Sí impresionista por el tempo de aproximación a todas las caras posibles de la realidad. Es el apasionado programa que se traza en su obra mayor, la Filosofía del dinero ${ }^{12}$.

«La unidad de estas investigaciones [reside] en la posibilidad, que está por demostrar, de que se puede encontrar la totalidad de su sentido en cada singularidad de la vida... La unión de las singularidades y las superficialidades de la vida con sus movimientos más profundos y esenciales y su interpretación, según su sentido general, se puede realizar tanto desde la perspectiva del idealismo como desde la del realismo, desde la razón como desde la voluntad, desde la interpretación absolutista del ser como desde la relativista.»

Esta intuición, de base indudablemente hegeliana, que apuesta por hallar en los hechos su propia teoría y tomar lo concreto como síntesis de determinaciones plurales, es el punto central de su mirada sobre la sociedad. Por eso no desdeña, y en eso es maestro de los mejores fabulistas del bazar moderno, ni el tratado heteróclito ni las viñetas sobre el adorno, los viajes, el consumo de cigarrillos (y, sorprendentemente, ya no de cigarros). De cualquier objeto de consumo es capaz de sacar conceptos para ilustrar un territorio global - tan cercano en su basamento al consumo como hecho social global, de Marcel Mauss - para el que propiamente no hay mapa previo, puesto que los grandes almacenes que modifican la Wittenbergplatz ${ }^{13}$ son de nueva implantación y,

${ }^{10}$ L. Coser, o.c., Introducción, p. 1.

11 Catálogo de la exposición "La ciutat de K. Franz Kafka i Praga», Centre de Cultura Contemporania, Barcelona, 1999.

${ }_{12}$ G. Simmel, Filosofia del dinero, Madrid, Instituto de Estudios Políticos, 1976, pp. 12 y 13.

${ }^{13}$ Véase al respecto el artículo lleno de sugerencias de José M. ${ }^{a}$ GonZÁlEZ GARCía, "Los riesgos de la autenticidad", en La Balsa de la Medusa, núm. 34, 1995, pp. 27 y ss. En el comienzo (Un paseo benjaminiano por Berlín) nombra la plaza y el primer gran almacén. KaDeWe —Kaufhaus des Westens_-, inaugurado en 1907, poco después de la aparición de la gran obra de Simmel. 
además, no cesan de cambiar su fisonomía. Éste es origen del punto de vista del fabulador que incorpora su hábitat en su estilo. Alguien que nace en 1858.

«En la intersección de la Leipzigstrasse y la Friedrichstrasse. Todavía situadas entonces al oeste del viejo centro de la ciudad, estas dos calles llegarían a ser las calles comerciales más típicas e importantes. No era posible ser más berlinés cuando uno había nacido en la esquina de la L y la $\mathrm{F}^{14}$.

Como huésped, como viajero, dice quien mejor aplica sus tesis a la incipiente sociedad de consumo de masas, Sigfried Kracauer, Simmel "posee la capacidad de asociación, el don de percibir relaciones y la unión significativa de fenómenos arbitrarios. Simmel es un eterno viajero entre las cosas. Su ilimitada capacidad de combinar le permite desplazarse en cualquier dirección desde cualquier punto» ${ }^{15}$. Esta característica de la hipersensibilidad, de la hiperestesia del consumidor conspicuo, que tiene afinidades en ensayistas de la sociedad de consumo europea y española, como Ortega o Gómez de la Serna ${ }^{16}$, le lleva a realizar, en expresión de Nisbet, una sociología como forma artística ${ }^{17}$. Lo que significa, a mi entender, que la forma de contar las cosas del centro social perdido en la multiforme expansión de las mercancías se convierte a su vez en algo sintomático, en un objeto regido por las leyes de la cultura escópica, esteticista, que trata de descifrar. Así se puede entender bien la importancia contextuada del uso del ensayo por Simmel, como forma de indagación y exposición. El ensayo, dice Adorno, rehúsa la definición de sus conceptos e incorpora el impulso antisistemático en su propio procedimiento e introduce «inmanentemente» conceptos sin modificar, tal como los recibe ${ }^{18}$. Éste es precisamente el modo en que su aproximación al universo del consumo resulta tan atractiva como abierta, es decir, perseguidora no del sistema, sino de lo sistemático, esto es, de lo significativo ${ }^{19}$.

El que Frisby llama el sociólogo más convincente de la cultura metropolitana, lo es precisamente porque incorpora muy pronto y con gran precisión dos fenómenos complementarios, en apariencia, que forman la tensión del primer escenario del consumo: la integración en un sistema que se presenta por

${ }^{14}$ Hans Simmel, "Auszüge aus den Lebenserinnerungen», en H. Böhringer y K. Gründer (comps.), Äesthetic und Soziologie um die Jahrhundertwende: Georg Simmel, Frankfort, Klosterman, 1978, pp. 247-248, citado en D. FrisBY, Georg Simmel, México, Fondo de Cultura Económica, 1990, p. 29.

15 S. KraCauer, Georg Simmel [manuscrito, p. 37], en D. FrisbY, G.S., México, FCE, 1990, p. 23.

${ }^{16}$ J. M. Marinas, «El bazar efímero: imágenes del consumo de Gómez de la Serna», en La Balsa de la Medusa, núm. 50, 1999.

17 R. Nisbet, G.S., Londres, Heinemann, 1976.

18 «Der Essay als Form», en Noten zur Literatur, vol. I, Frankfurt, Suhrkamp, 1958, citado por David Frisby y Mike Featherstone, Introducción a Simmel on Culture, Londres, Sage, 1997.

19 La distinción es de Roland Barthes, en Sade, Fourier, Loyola, París, Seuil, 1970. 
vez primera como un gran mercado y el afán de diferenciación como respuesta a esa gran trama que amenaza con homogeneizar primero y masificar, engullir, después.

Por primera vez se presentan en el espacio urbano las mercancías como el sentido último y como el elemento aglutinador y omniabarcante de toda la vida. Las exposiciones universales ${ }^{20}$ son algo más que un espacio al margen de la vida. Son la muestra de este nuevo sistema de relaciones que se ofrece como modelo y ante el que las estrategias de selección - consumo conspicuo- y emulación son mucho más que actitudes de compra: definen al sujeto social entero. Estos nuevos sujetos que constituyen fragmentos de un todo social más amplio que sólo parcialmente, según Frisby ${ }^{21}$, es visible en la intersección de los diversos ambientes y grupos sociales.

De estos rasgos de su contexto se sigue bien el derrotero teórico y metodológico de Simmel al abordar la cultura del sistema capitalista, en la medida en que va apareciendo como un sistema no sólo de producción, sino como un modo de vida que abarca las esferas de la vida cotidiana. Primero lo hace con la ética de la maximización — que encontrará en Weber, como es sabido, su mejor teorizador-, pero luego, en una simultaneidad de contradicción aparente $^{22}$, con la estética del despilfarro, con el valor representacional de objetos, mercancías y marcas. El sistema de la producción resulta opaco en la medida en que los procesos productivos se ocultan bajo la lógica del fetichismo de la mercancía (Marx), el sistema de los objetos aparece como el relevo clarificador en la medida en que organiza las pautas, expresa las identidades, segmenta las nuevas clases. Por eso, Simmel se distrae, en apariencia, por los derroteros de los objetos de la vida cotidiana: el adorno, las maneras de mesa, va de los espacios «importantes» para la filosofía y la ciencia social clásicas a los nuevos espacios realmente importantes para los ciudadanos de la sociedad de la abundancia de mercancías. Importantes aunque eéstos, en el atomismo de sus crecientes interacciones, en el individualismo a partir de la fragmentación de sus experiencias, no tengan aún palabras para nombrar lo que les pasa. Y lo que hace con el desplazamiento de espacios: una sociología de los objetos en combate, tensión y seducción respecto de los sujetos, lo hace también con el tiempo. Siendo un progresista cabal, como berlinés, vuelve como sociólogo atrás y al presente de una manera que sorprende.

20 De la importancia de este fenómeno, a partir sobre todo de Benjamin y de otros clásicos del protoconsumo, he dado cuenta en "La fábula del bazar: ética y cultura del consumo", en Revista de Occidente, núm. 162, noviembre 1994, pp. 166-183, y en «Paisaje primitivo del consumo: Analogía frente a alegoría en el Passagen-Werk de Benjamin", en La Balsa de la Medusa, núm. 34, pp. 6-26.

${ }^{21}$ D. FrISBY, o.c., 1990, p. 32.

${ }^{22}$ El síntoma que analizo en estos trabajos de los clásicos del consumo, que actualmente compongo bajo el título genérico de La fábula del bazar (en preparación), es que coexisten precisamente teóricos del consumo productivo (Weber) con los del consumo conspicuo o improductivo (Veblen, Simmel, Mauss, Bataille, Benjamin). La transición de una forma a otra en la cultura concreta no es abrupta, sino gradual y llena de tensiones, avances y retrocesos. 
Eso explica la aparente regresión ${ }^{23}$ que emprende a otras formas de consumo e intercambio - en un curioso paralelismo con Veblen y con Mauss o con el propio Benjamin del "paisaje primitivo del consumo»— como ejemplo de los modos de autopreservación de los grupos sociales, desarrollada por primera vez de forma sistemática en su obra Sobre la diferenciación social (1890). Y también explica su manera peculiar de ver los fenómenos sociales como exigiendo éstos una mirada acorde con su nuevo tiempo propio - que no sería el tiempo largo de las tendencias de la filosofía de la historia-. Esto supone tomarse el tiempo presente a contrapelo. Proponer a la indagación sociológica otra manera de ver el tiempo centrada en el presente y su densidad sorpresiva. Como le ocurre, quiero precisar, al ciudadano de los primeros grandes almacenes, que ve los días y las horas, los gustos y las preferencias alterados por un incesante proceso de innovación que hace que nada se pueda acumular, ni siquiera las formas que más identificaban en la industrialización primera.

Esta percepción del «instinto de la época» (Fechter), o, como dice en 1911 Alfberg, esta perspectiva simmeliana, «enfocada tan fuertemente al presente ${ }^{24}$, le sitúan en un campo nuevo muy propio de la cultura que el consumo inaugura: lo que se da es un nuevo modo de experimentar la vida contemporánea. De ahí la exigencia de su método y perspectiva: su opción radical por la interacción frente a una sustantivación de la sociedad y al mismo tiempo, como paradoja, la apuesta por un plano global y ya no individualista en el terreno de las explicaciones de pautas y representaciones sociales. Preocupado por las nuevas formas de agrupación, por la estructura de los grupos, Simmel muestra en esos mismos trabajos, de apariencia sosegada, la presión vital de los recientes modos de desagregación y exclusión que la sociedad establece. Por eso se puede entender el arraigo en su tiempo y en su espacio. Quien se permite una salida de los modos historicistas y ambientalistas tradicionales, vive y nombra su condición metropolitana y concreta. Tenemos, pues, como primer ingrediente de la mirada sobre el consumo, la razón y el estilo de un ciudadano que, pese a las distancias que toma para observar lo que viene, no cierra los ojos a su entorno concreto. Pareciera que una de las cualidades del Simmel que observa y va calando la ciudad del consumo incipiente se debe precisamente a su capacidad de mirar, que le viene de su condición berlinesa. Así lo nombra René König:

«Tal vez no sea ninguna casualidad que el primer análisis original de los fenómenos de la gran ciudad en habla alemana no viene de ningún investigador académico, sino del filósofo judío Georg Simmel, que había nacido en Berlín ${ }^{25}$.

${ }^{23}$ D. Frisby, "Georg Simmel and Social Psychology», Journal of the History of the Behavioral Science, vol. 20, 1984.

${ }^{24}$ D. FrisbY, o.c., 1990, pp. 59-60.

${ }_{25}$ René KöNIG, Soziologie in Deutschland, Begründer/Verächter/Verfechter, Munich, Hanser, 1987, p. 330. 
Entre los datos biográficos de Simmel —a falta de una biografía suficiente a estas alturas- está la paradoja de su condición cosmopolita: la de un ciudadano y consumidor universal y el apego a Berlín más allá de lo razonable en quien podía tener un reconocimiento académico, vinculado a su disponibilidad. En 1914, con 56 años, a punto de ir ya como catedrático a Estrasburgo, escribe: «si lo acepto no es con un ánimo radiante. La influencia sobre la cultura fiosófica que puedo ejercer en Berlín no es algo alcanzable en cualquier lugar $»^{26}$.

\section{UNA METÓDICA PARA EL SUJETO CONSUMIDOR}

¿Cómo es el nuevo sujeto de la sociedad de consumo? Si podemos sintetizar en sus rasgos principales la caracterización plural que Simmel hace en sus ensayos paralelos a la redacción de la Filosofía del dinero, podemos sugerir los siguientes: se trata de un sujeto dotado de una nueva cultura, afectado por la fragmentación de la vida en las ciudades, marcado por la técnica, mediado por las mercancías.

La nueva cultura abarca, en la perspectiva de Simmel, desde las formas de creación de nuevos valores a la mediación de éstos en el mercado y la vida cotidiana. Se trata de un nuevo concepto para capturar una nueva realidad. Simmel, formado filosóficamente en la transvaloración nietzscheana, persigue en el contexto del consumo una génesis de los valores. Es decir, compone una noción de cultura en la que es originariamente tan de Nietzsche (el mejor visionario de las raíces poderosas de los valores) y de Hegel (la dialectización de lo objetivo y lo subjetivo, del reconocimiento como condición de la identidad) como de Kant y Goethe (con la universalización moral y la dramatización de la vida como escenarios de la modernidad). Este plano conceptual, que merece amplios y doctos comentarios en la recepción actual de Simmel, tiene su correlato en la crítica de la cultura que el Simmel sociólogo emprende. La intuición de base es que en ella, más que el punto de llegada de una tendencia -la complección del industrialismo con el consumo-, el sistema prepara, para su propia reproducción, el revés de la sociedad capitalista productivista.

Por ello, Simmel no sólo redefine, como veremos a continuación, la Historia, la perspectiva de análisis de la modernidad, la misma temporalidad, sino que construye un modelo distinto de la relación ente cultura y sociedad. El punto de engarce entre lo sistémico y lo cultural es la pluralidad de espacios que la sociedad compleja, movida por el monetarismo o la simbólica de la forma-dinero, de la forma-adorno, de la forma-técnica, está empezando a generar. Esta redefinición de espacios, de formas de interacción, es una visión estilizada — lo que Kracauer y Frisby llaman «intemporal»— de la sociedad del

${ }^{26}$ En D. Frisby, en el «General Commentary» con el que abre su edición de Georg Simmel. Critical Assessments, Routledge, Londres y N. York, 1994 (sin número de página). 
protoconsumo. No hace una fenomenología del consumo de bienes, en sentido socioeconómico, y sí hace una analítica de las formas en las que los nuevos espacios y bienes de consumo configuran nuevas formas de sociación. Su posición ante la polémica de los economistas - psicologización de las motivaciones- le lleva a poner de manifiesto el valor de formas culturales e interactivas nuevas que no son individuales, sino socializadoras de nuevos modos, incluyendo un sintomático nuevo individualismo.

La cultura es el conjunto de los modos de producir las formas de interacción y sus mediaciones que prefiguran y generan formas de vida, incluso las no previstas. No son formas estáticas, son procesos. Los compone la subjetividad intencional formada que emerge de la vida humana y sus interacciones, y es creada por los seres humanos como contenidos objetivados o como entidades de lenguaje, religión, órdenes normativos, sistemas legales, tradiciones, artefactos artísticos, etc. ${ }^{27}$. Este proceso de objetivación del sujeto, que es al mismo tiempo la "desubjetivación del individuo», implica, como Guy Oakes ha formulado, siguiendo los términos de Simmel, que la cultura es

«el proceso en que la vida se reproduce a sí misma como "más vida” y se trasciende a sí misma generando formas que califica como "más que vida". Simmel representa la cultura como un proceso de dos dimensiones. Por una parte, las energías e intereses de la vida son definidas y modeladas por las formas de la "cultura objetiva", el mundo de las formas culturales y sus artefactos que han llegado a ser independientes de la existencia individual... Por otra parte, estas formas culturales y sus artefactos son incorporados en la "cultura subjetiva" del individuo, el estado de la personalidad que es el último resultado del proceso de cultivación... La cultura subjetiva es la cultura personal de individuo, o la vida del individuo como un ser cultural $»^{28}$.

Esta dialéctica incesante muestra bien la estrategia del diagnóstico que Simmel reproduce en numerosos trabajos. No importa sólo desmontar la cosificación: el peso de los objetos como ocultadores de las relaciones de producción y explotación (Marx) y los conflictos de identidad que eso produce, sino mostrar el modo en que los sujetos componen activamente formas mentales, instrumentos, pautas, para suturar esos conflictos, nombrar lo silenciado, producir identificaciones. Lo actualiza en el análisis sobre el adorno (Exkurs über den Schmuck).

«Uno se adorna a sí mismo para sí mismo, pero sólo puede hacerlo mediante el adornarse para otros. Es una de las combinaciones sociológi-

Introducción a Simmel on Culture, Sage, 1997, p. 5.

${ }^{28}$ Guy Oakes (ed.), Georg Simmel: On Women, Sexuality and Love, New Haven, Yale U. Press, 1984, pp. 6-7. 
cas más raras el que un acto, que sirve exclusivamente al énfasis y aumento de significación del actor, sin embargo alcanza exclusivamente su objetivo en el agrado, en el deleite visual que ofrece a otros y en su gratitud» ${ }^{29}$.

Esta dialéctica de lo subjetivo y lo objetivo queda claramente expuesta en el caso de un campo de objetos de consumo tan central como el del adorno. Dicha dialéctica es el motor de los nuevos valores, de las nuevas formas en las que se ve la interimplicación yo-otro en la cultura subjetiva, en la formación del sujeto. Éste es el esquema que, como apuntaremos, aparece en las reflexiones sobre el dinero y la moda.

El sujeto de esta sociedad de riqueza ostensible y de marginaciones renovadas no es, como decía Ernst Bloch, un sujeto macizo. Es un sujeto afectado por la fragmentación de la vida en las ciudades. Lo que significa que la identidad de atribución se ve sustituida por los numerosos escenarios y la circulación de las mercancías. La noción de circulación (Verkehr) puede venir bien como primera matriz perceptiva de un mundo cambiante regido por el intercambio incesante de las mercancías, de las modas y, consiguientemente, de los estilos de vida, de los modos de vivir. Como ocurre con Kafka, la percepción es más poderosa que el concepto que de ella se extrae. En Kafka, eclosiona en dramas y tramas de novela; en Simmel, en ensayos y retratos en los que, como el praguense mostraba, se trata de poner de relieve lo que ya está en la superficie y no se sabe nombrar. Lo están viviendo pero no lo saben archivar con un rótulo adecuado. Posiblemente porque tales experiencias, en su novedad radical y en su ruptura, no tienen parangón.

Hay un giro fundamental en lo espacial y su representación. Pero no en el sentido ambientalista abstracto, sino la ciudad que se rompe con la descentralización del mercado. Los pasajes comerciales y las nuevas avenidas son el emblema de ello. En el plano de los sujetos, supone el revestimiento íntimo de una urbanidad metropolitana: es un espacio múltiple y multiforme de relaciones y de consumo; pero también de nuevas formas de dependencia y subordinación; los estilos mentales del mercantilismo.

La primera forma de detectar el problema es precisamente la huella que el nuevo orden urbano deja en el sujeto que quiere ser libre y crear sus propios valores. La ciudad marca de fuera adentro, del mercado a la identidad personal ${ }^{30}$. La ciudad es otro fenómeno privilegiado en el que el concepto dialéctico de cultura se ejercita con precisión. Retengo algunos de sus rasgos principales.

El abordaje en su célebre trabajo sobre las grandes urbes contemporáneas ${ }^{31}$

29 G. Simmel, Exkurs uber den Schmuck, cito por la edición de K. WOLF, o.c., p. 338.

${ }^{30}$ Una primera formulación de las relaciones de Simmel y la ciudad la expuse en «Sujeto, identidad y medio ambiente», en N. MarTínez SoSA, Educación Ambiental: Sujeto, Entorno y Sistema, Salamanca, Amarú Eds., 1989, pp. 123-139.

31 G. Simmel, «Las grandes urbes y la vida del espíritu», en El individuo y la libertad, Barcelona, Península, 1989, pp. 247 y ss. 
comienza con la ciudad como resultado del proceso productivo que en la actualidad el crecimiento exige y produce una nueva forma: «el carácter intelectual de la vida, el cálculo y la racionalización como un órgano de defensa frente al desarraigo con el que le amenazan las corrientes y discrepancias de su medio ambiente externo». Pero el rasgo que anima la innovación es la aglomeración del intercambio económico, que acaba produciendo radicalmente nuevas formas de interacción —otra vez la fluidez frente al sistema-, lo que trae nuevas percepciones y sentimientos.

«La moderna gran ciudad se nutre casi por completo de la producción para el mercado, esto es, para consumidores completamente desconocidos que nunca entran en la esfera del auténtico productor $\aleph^{32}$.

Vemos bien aquí cómo la descripción de un fenómeno tiene una lectura conceptual más profunda: el paso del capitalismo de producción al de consumo se percibe directamente en la especialización y la segmentación. Y, también, en la misma perspectiva de dar de un fenómeno todas las facetas del prisma, con la invención de sentimientos que son propios de esta nueva cultura. Por ejemplo, la agorafobia, como patología metropolitana, como marca del extrañamiento ${ }^{33}$. Especialización según el mercado, extrañamiento, racionalización y cálculo, nuevos sentimientos incontrolables. Como recoge Vidler, las dimensiones novedosas de la primera ciudad del consumo en la tradición simmeliana son "estos espacios emblemáticos — que los seguidores de Simmel, como Benjamin, Kracauer o Adorno, repasan críticamente- [que] frecuentan sus textos como simbolizando cada aspecto del nomadismo, del fetichismo del consumidor, y del individualismo sin sitio de la vida moderna en las grandes ciudades». Carácter vertiginoso y proteico que Kracauer plasma así en palabras plenamente simmelianas: "el flâneur está intoxicado con la vida en la calle - vida que eternamente disuelve las que está configurando ${ }^{34}$.

Configuración es, como vemos, palabra dual en la medida en que encierra forma y proceso. Configuración es el modo en que la mente se ve afectada por la técnica, rasgo central de la nueva cultura, en la medida en que las pautas del consumo superan la mera utilidad de lo producido: los bienes no se consumen, troquelan al consumidor. Selecciono, como ejemplo, algunos pasajes de su célebre ensayo sobre los cambios en la cultura alemana de fin de siglo ${ }^{35}$.

32 G. Simmel, «Las grandes urbes y la vida del espíritu», o.c., p. 249.

33 A. VIDLER, "Agoraphobia: Spatial Estrangement in Georg Simmel and Siegfred Kracauer", New German Critique, 1991, pp. 31 y ss. Ver también Carl SCHORSKe, "The idea of the City in European Thought", en Oscar Handlin y John Burchard (eds.), The Historian and the City, Cambridge, MIT, 1966, pp. 95-114.

${ }^{34}$ S. Kracauer, "Once again the street», en Theory of film: The Redemption of Physical Reality, N. York y Londres, Oxford University Press, 1960, p. 72.

35 G. Simmel, "Tendencias en la vida y el pensamiento alemanes desde 1870", The International Monthly, vol. 5, 1902, pp. 93-111 y 166-184, en D. Frisby (ed.), o.c., 1994, vol. I. 
El término elegido es la cultura monetaria - que desarrolla en paralelo en la Filosofía del dinero - entendida como red de símbolos y pauta de interacciones. Pero el troquelado es, como ocurre con la ciudad, radical. La primera exhibición exigida por la cultura del consumo de elementos antes reservados (la fruición del dinero, el disfrute de los nuevos objetos) cambia la mentalidad entera:

«Los poderes de la mente se han visto forzados a servir a los propósitos de ganancia pecuniaria de un modo antes inaudito en Alemania, y gobernados por una competencia extraordinariamente activa, tanto nacional como internacional, para lograr que todas la demás cosas se subordinen a los intereses materiales. Como resultado de todo esto, la técnica se ha convertido en los últimos años en la única preocupación de productores y consumidores, y de un modo que es más ominoso para el desarrollo interior y espiritual de la nación.»

El punto de vista de Simmel no deja de tener, pese a su enorme apertura a los fenómenos, un timbre irónico y moralizante. El retrato del contexto concreto del consumo doméstico e interurbano es enormemente expresivo.

«Está completamente olvidado que la técnica es un mero medio para un fin, y su perfección queda excluida cuando se la piensa como uno de los grandes objetos de la raza humana; como si telégrafos y teléfonos fueran en sí mismos cosas de extraordinario valor, pese al hecho de que lo que los hombres se dicen unos a otros por medio de ellos no es en absoluto más inteligente, más noble, o en modo alguno excelente de lo que antes confiaban a medios menos rápidos de comunicación; como si la luz eléctrica elevase al hombre a un estadio más cercano a la perfección, pese al hecho de que los objetos más claramente vistos por medio de aquélla son precisamente tan triviales, feos o carentes de importancia como cuando eran vistos gracias al petróleo.»

Y la secuencia se concluye con la reflexión, la extensión de los hallazgos a otros campos sancionados como autónomos o ajenos a las tendencias de la moda, que es la vigencia del presente del consumo.

«Esta primacía de la técnica ha inficionado incluso las ramas puramente intelectuales del conocimiento: tanto en las ciencias históricas como en la psicología experimental, investigaciones esencialmente banales $y$, desde el punto de vista del objetivo final de toda investigación, aún más sin importancia, gozan frecuentemente de un grado muy desproporcionado de reconocimiento, que sólo se lo confiere el que han sido realizadas mediante procedimientos metódicos y técnicos perfectos.»

Estos rasgos nos dan una primera formulación de la identidad del nuevo sujeto marcado por las mercancias. Éstas tienen el carácter no de meras cosas 
dirigidas a un consumo individual, sino que son formas. Objeto de reflexión para esa sociología que Simmel entiende como "descripción y determinación del origen histórico-psicológico de las formas en que tienen lugar interacciones entre los seres humanos» (Superioridad y subordinación). Carácter de forma y lugar de construcción de valores precisamente al hilo de estos objetos que son modos de relación.

Y ello aunque no se niegue la fuerza mimética que las relaciones y, en general, la condición humana experimenta a partir de la fascinación de los nuevos objetos, hasta el punto de convertirse en atractor de una nueva alienación.

«La gran perfección del objeto ha desplegado la imperfección del sujeto, y ha mostrado que el desarrollo de este último, no más que el del primero, debería ser dejado a la suerte, al instinto, al curso sin meta de la naturaleza» ${ }^{36}$.

Como pendant de esta cosificación fascinante, el sujeto del consumo, como se ve en el excurso sobre el adorno, pugna por apropiarse los objetos y por pertenecer a los perfiles que anticipa su forma, su mundo. Por eso, en el enfoque de consumo la categoría de pertenencia - a un status en Veblen, a un estilo en Simmel - es central desde el principio. Frente al semiologismo del circuito de la comunicación, el elemento social que cobra importancia es el valor de integración mediante el objeto o el bien. Frente al objetualismo, el valor de "pertenencia" a una esfera de objetos con valor para un grupo o sociedad. En este sentido puede matizarse la tesis de Frisby según la cual Simmel no se ocupa tanto del consumidor como del mundo del intercambio de mercancías y su efecto en las relaciones sociales y en las formas de sociación. Si lo que se tiene en la cabeza al hablar de consumidor es el modelo individualista preferencialista, de acuerdo. Si lo que designamos como consumidor es un sujeto en relaciones y en proceso, con las mediaciones que acabamos de indicar, por supuesto que Simmel no sólo se ocupa de él, sino que traza los primeros fundamentos para su análisis sociológico ${ }^{37}$.

Éste es, pues, el arranque de la perspectiva moderna que desplaza el acento del intimismo del sujeto, del preferencialismo individual, hacia el estudio de las formas de configuración de la cultura del consumo. Para luego volver a la formación de la intimidad, de la identidad de los consumidores.

La noción de objeto como red de relaciones — que a Simmel le viene de su primer trabajo sobre Kant- se puede aplicar a los objetos de consumo. No sólo a la idea abstracta de ellos en la sociedad, sino al análisis concreto de esta fase. La interacción (Wechselwirkung) de los elementos es la que representa y anticipa la interacción de los sujetos. La figura y su representación superan, pues, una mera mirada cosista al universo del consumo. Simmel recoge aquí su

${ }^{36}$ G. SimmeL, «Tendencias en la vida y el pensamiento alemanes desde 1870», o.c., ibid.

37 D. FRISBY, o.c., 1984, p. 66. 
reivindicación de la perspectiva estética, que no es marginal, sino central en las relaciones del consumo ${ }^{38}$ : el sentido del universo del consumo presente en cada objeto. Cualquier circunstancia, dice Simmel, esconde la posibilidad de liberar un significado estético absoluto. Para la mirada debidamente entrenada, la belleza total, el significado total del mundo resplandece en una sola circunstancia específica. Por eso, la sociología de Simmel desarrolla una estrategia de atención a las circunstancias de la interacción humana en los nuevos espacios y tiempos del mercado: atento, en las maneras de mesa, las relaciones en los transportes públicos, en las comunicaciones escritas, etc., a la "posibilidad de encontrar en cada uno de los detalles de la vida la totalidad del significado de ésta ${ }^{39}$.

Retengamos, pues, que esta nueva fundación del sujeto social implica una relación peculiar con las mediaciones señaladas: la cultura, la ciudad, la técnica, las mercancías. La sociedad de consumo incipiente trae consigo la ruptura del tiempo y del espacio. Pero también las identidades y los rasgos de pertenencia a los grupos sociales. El extranjero, el secreto, etc., son otros tantos signos de una sociedad que se fragmenta por el proceso de industrialización y - tal vez aquí radica su mayor originalidad- se sutura intencionalmente configurando un nuevo todo en las formas del consumo.

\section{EL DINERO Y LA FORMA MERCANCÍA}

«El dinero no es más que un medio, un material o un ejemplo para la representación de las relaciones que existen entre las manifestaciones más externas, reales y contingentes y las potencias más ideales de la existencia, las corrientes más profundas de la vida del individuo y de la historia $»^{40}$.

El carácter troquelador de los procesos técnicos sobre las mentalidades y las subjetividades modernas encuentra su apogeo en los fenómenos del intercambio económico. Éste es definido como una de las formas de intercambio social, estructura principal y general, y encuentra su condensación y su modelo operativo en el intercambio mediado por el dinero.

La Filosofía del dinero, obra sintomática del cabo de siglo — como la Teoría de la clase ociosa de Veblen, las Formas elementales de la vida religiosa de Durkheim, o la Interpretación de los sueños de Freud-, ha merecido y merece un sinfín de comentarios y análisis desde el punto de vista de la crítica de la cultura y de la actividad económica. Nuestro punto de vista aquí se reduce a mostrar cómo aparece la lógica interna de la sociedad de consumo incipiente en el

${ }^{38}$ G. Simmel, «Soziologiche Äesthetik», en Die Zukunft, vol. 17, 1896, pp. 204-216.

39 G. Simmel, Filosofía del dinero, Madrid, Instituto de Estudios Políticos, 1976, p. 55.

${ }^{40}$ G. Simmel, Filosofía del dinero, o.c., p. 11. La cursiva es mía. 
contexto de un trabajo que no la enfoca directamente como tal - su pretensión es el advenimiento del auge y homogeneidad de la forma dinero en el tránsito a la modernidad-, pero que sí esboza los desarrollos teóricos y conceptuales que fundan la indagación simmeliana del tiempo y los fenómenos del consumo. Los rasgos que destacan, en esta dirección, aquellos en los que Simmel inaugura un lenguaje de hoy, son: el carácter global y no sólo económico del consumo y del intercambio representado en el dinero; la superación del concepto de necesidad y la atención al deseo en la relación con las mercancías; la fundamentación de un concepto de mercancía y de valor que pretende leer los implícitos de Marx; la lectura del consumo no desde el preferidor individual, sino desde el concepto de estilo de vida.

El carácter global y no sólo económico ha sido suficientemente repetido en los comentaristas clásicos de Simmel que han glosado su declaración inicial: «en esta investigación no hay ni una línea escrita en el espíritu de la economía política» ${ }^{41}$. Lo importante es su intento de una analítica de los intercambios y una reflexión de los detalles, en el sentido dicho, a propósito de la nueva cultura del dinero. Para entender el consumo, el primer elemento es precisamente el dibujo de su carácter global.

El consumo moderno, según los presupuestos de Simmel, pide una forma de análisis en la que el marco cultural no es un mero epifenómeno. Le interesa exponer las precondiciones de una cultura marcada por el gran intermediario, traductor y acumulador que es el dinero. Dichas precondiciones se localizan en los estados mentales, en las relaciones sociales y en la estructura lógica de la realidad y de los valores. Ellas son las que otorgan al dinero su significado y su posición práctica. Por ello no es una lectura culturalista de las relaciones económicas, sino una lectura integral de las formas de intercambio, entre las que están las de la moderna economía.

La demanda de los sujetos - en la que se detecta la primera fuente de los valores, en consonancia con los teóricos contemporáneos de la utilidad marginal- implica una primera mirada sobre el consumo como forma de cultura en el sentido dicho. Hay un énfasis en el intercambio de bienes, incluso un subrayado novedoso: para Simmel, el intercambio es tan productivo y tan creador de valores como la producción misma. De ahí el carácter global de la mirada cualitativa que intenta leer también el proceso económico en lo que sucede en la mente de cada sujeto. Los objetos económicos sólo alcanzan a recibir su significado pleno cuando se establecen con ellos relaciones de consumo; no tienen sentido, dice Simmel, excepto directamente en nuestro consumo y en el intercambio que tiene lugar entre ellos. Esta ecuación interacción-intercambio, que recoge las determinaciones teóricas ya señaladas, es la primera pista para entender el consumo, mediado por el dinero, como un fenómeno social total.

Fenómeno cuya globalidad alcanza a dimensiones que la perspectiva utilitarista o atomista no ha tenido en cuenta. El carácter totalizador es tal porque

${ }^{41}$ G. Simmel, Filosofía del dinero, o.c., p. 11. 
implica todas las dimensiones de los sujetos sociales. Esta «invasión» en lo previsto, más allá de la conciencia de los participantes, se realiza precisamente por el intermediario de ese sistema canónico de los intercambios que es el dinero. Pero a sabiendas de que se trata de un sistema mediador, no de la fuente del valor mismo. Así lo formula y lo matiza Simmel:

«Parece evidente $[. .$.$] que la remisión del valor material del dinero a un$ principio suplementario y de consolidación frente a las meras relaciones, tan difíciles de asegurar, no es sino la primera indicación de un proceso que se produce por debajo del sustrato de la conciencia de los que participan en la actividad económica... Con todo, no conviene olvidar que las representaciones inconscientes no constituyen ninguna explicación satisfactoria, sino que solamente son una expresión auxiliar que en realidad descansa sobre un razonamiento falso... En el estadio actual de los conocimientos es inevitable, y por lo tanto legítimo, interpretar las construcciones de valor, sus rigideces y sus fluctuaciones como procesos inconscientes, según las normas y las formas de la razón consciente» ${ }^{42}$.

Resulta interesante este pasaje por mostrar una misma intención de desvelar lo oculto y, al mismo tiempo, no cejar en cuanto al racionalismo como metódica que sirve en la exploración de las anomalías. No hay, claro está, en el uso de lo inconsciente ninguna de las connotaciones freudianas. Y, sin embargo, sí parece, a lo largo de la argumentación, que Simmel — sin duda vía Nietzsche - propone una mirada de las reglas de juego que superan la llamada filosofía de la conciencia. Decir inconsciente aquí es decir aún no sabido; por tanto, insatisfactorio como explicación. Pero, al tiempo, decir inconsciente significa convenir en que el plano de lo descriptible y contable es la expresión de un sistema de reglas sociales aún no desveladas pero ya en acción. Más allá de la atribución convencional y cegadora de una benéfica «mano invisible», Simmel indaga lo complejo culturalmente de la fuente del valor. La forma mercancía encuentra un soporte en las relaciones sociales y culturales de las que, según Marx, es horma y modelo inconsciente. Estas relaciones sociales y culturales son el entramado del que surge la nueva producción de valores, cuya fuente es subjetiva ${ }^{43}$ :

«Comoquiera que uno y el mismo objeto puede representar el grado más elevado del valor para un alma y el más bajo para otra y que, por el contrario, la diversidad más universal y manifiesta de los objetos puede unirse en una igualdad de su valor, parece que el origen del valor sólo puede ser el sujeto con sus estados de ánimo y reacciones normales o especiales, duraderas o cambiantes.»

${ }^{42}$ G. SIMMEL, Filosofía del dinero, o.c., p. 162.

${ }^{43}$ G. Simmel, Filosofía del dinero, o.c., p. 22. 
Simmel enfrenta la creación de valores en el proceso de intercambio precisamente como un proceso en el que está en juego la totalidad de las relaciones sociales y de las dimensiones de los sujetos. El valor es una dimensión creativa (otra vez Nietzsche), no resulta de mera herencia, sino de la articulación de las nuevas formas de las necesidades y los deseos. Ése es el contexto de la Filosofía del dinero, que en su origen pretende, como es sabido, construir una «filosofía de toda la vida histórica y social». Su mismo estudio previo, el artículo «Sobre la psicología del dinero", escrito en 1889 y que aparece en 1890, indica este carácter de verdadera mirada antropológica y sociológica allí donde antes — quizá con la excepción de Marx- ha predominado una mirada economicista, acotada. Simmel da pie, desde nuestra visión actual, a algunos desplazamientos - y a ellos me ciño- enormemente creativos en el orden del concepto de deseo frente a la necesidad, las mercancías y el estilo de vida.

El dinero es un medio, un material o un ejemplo para representar una dinámica más profunda. Éste es el programa que sirve para desmontar, además de la ecuación consumo-individuo, del individualismo economicista, otra ecuación tradicional: la que equipara consumo y necesidad. Cuando Simmel afirma al comienzo de su obra que «la significación final del dinero no reside en él mismo sino en su transferencia a otros valores», está situando una posición puente entre la visión de Marx — la génesis del valor de cambio como equivalencia- y la visión culturalista de Weber. Va del reino de la necesidad al del deseo. Perspectiva ésta que, curiosamente, encuentra su correlato en la lectura que Ortega hace de Sombart ${ }^{44}$, cuando señala el deseo y no la necesidad como rasgo del desarrollo de la cultura del consumo incipiente.

La génesis del valor encuentra en la relación de distancia con el objeto su apertura a la problemática del deseo del consumidor, más allá de la necesidad. Solamente la experiencia del anhelo, del deseo, puede desgajar, dice Simmel,

«la unidad ingenua y práctica del sujeto y del objeto y, así, sitúa a ambos —uno a partir del otro- frente a la conciencia. Únicamente cuando anhelamos lo que aún no tenemos ni disfrutamos podemos situarnos ante su contenido. En la existencia empírica del hombre educado, el objeto no es deseado más que cuando se encuentra, ya preparado, frente a él $»^{45}$.

Los objetos y los bienes aparecen en la esfera del mercado no como algo capaz de satisfacer necesidades, de proporcionar elementos útiles, sino en cuanto objetos de deseo. Ésta es la primera realidad que vincula al sujeto y al objeto: éste «se nos opone y no sólo en la impenetrabilidad con que se nos apa-

${ }^{44}$ J. M. MARINAS, «Ortega: entre el casticismo y el consumismo», ponencia en el curso Filosofía, Literatura y Ciencias Sociales, UNED, Jávea, julio 1998.

${ }^{45}$ G. Simmel, Filosofía del dinero, o.c., p. 27. 
rece, sino de la distancia que supone el hecho de que aún no disfrutemos de él y cuyo lado subjetivo es, precisamente, el deseo ${ }^{46}$.

La fuente del valor de las cosas-mercancías depende, entonces, de la distancia que mantienen con los usuarios, de la disponibilidad o no. Así lo formula:

«El mismo momento del gozo en el que el sujeto y el objeto anulan sus contradicciones, consuma al mismo tiempo el valor, el cual sólo renace en la separación frente al sujeto, como su opuesto, esto es, como objeto [...] el valor no se origina en la unidad irrompible del momento de placer, sino en cuanto que su contenido, como objeto se separa del sujeto y en su calidad de cosa deseada, se enfrenta a él ${ }^{47}$.

De esa manera, tan aparentemente agónica, se explora una visión nueva del universo del consumo, en el que las cosas son valiosas porque ponen obstáculos a nuestro deseo de conseguirlas, y precisamente el universo de las mercancías se presenta a sí mismo como el gran facilitador del cumplimiento de los deseos. Lo que Simmel destaca es la producción de un mundo doble: el mundo autónomo de los objetos en oposición a un Yo que se postula como autónomo ${ }^{48}$. El valor resulta valor económico cuando se mantiene entre los umbrales posibles — determinados por el mercado - de esa relación entre dos mundos: es un cierto término entre escasez y no escasez (entre el recurso y la pobreza, dice, como el eros platónico) el que, en la mayoría de los casos, determina las condiciones del valor. El ejemplo de los bienes estéticos, de las obras de arte, corrobora, según Simmel, estos rasgos de todo bien económico.

A esta fenomenología del valor, arrancando del sujeto tal como lo caracterizamos más arriba, le sigue la incorporación del valor como sistema de equivalencias. De especial relevancia precisamente porque, en esta argumentación, Simmel incorpora su teoría de la cultura y de la sociedad como interacción a la mediación por las mercancías. Éstas no sólo establecen entre sí redes de relaciones que las convierten — si podemos utilizar el término baudrillardiano- en un sistema de los objetos del consumo, separados y cercanos, seductores y generadores de deseo. En el mismo momento en que incorporan los signos del mercado, las equivalencias forman también una red de sujetos deseantes que son el correlato de aquellas mercancías interrelacionadas. La interacción, categoría clave, vuelve a ser redefinida por cuanto se ve coloreada ahora por la relación desigual en el deseo de los bienes y mercancías.

El hecho del intercambio económico, en el que un objeto valioso encuentra su equivalente según las leyes del mercado, «libera a las cosas de su desaparición en la mera subjetividad de los sujetos y las permite determinarse recíprocamente», en la medida en que invierten en sí mismas su función económica.

${ }^{46}$ G. Simmel, Filosofia del dinero, o.c., pp. 26-27.

47 G. Simmel, Filosofia del dinero, o.c., p. 27.

${ }^{48}$ G. Simmel, Filosofía del dinero, o.c., p. 34. 
No es sólo el deseo el que otorga el valor al objeto, sino, dice textualmente, «el deseo de otro» ${ }^{49}$. Ésta es la vía argumental con la que Simmel, que comienza reconstruyendo el proceso del deseo individual, concluye en la realidad interactiva del intercambio económico y, lo que es más expresivo, en la idea de que es esta característica - que los sujetos se definen a partir de sus relaciones mutuas mediadas por las mercancías - la que nos hace aparecer la esfera económica como esfera autónoma y los valores como objetos de la economía.

«Lo decisivo en relación con la objetividad del valor económico, que delimita la esfera económica como esfera autónoma, es el hecho de que su validez trascienda, en principio, al sujeto individual $\aleph^{50}$.

La tensión entre la gratuidad en la que se presenta lo inmediato del consumo: el mero disfrute, dice Simmel, no constituye un acto económico — que lo relaciona con alguna de las anotaciones de Mauss sobre el don- y las férreas equivalencias con que se muestran en el mercado los sistemas de objetos-mercancías sitúan bien el lugar del dinero como pauta del valor. Las mercancías y el dinero se presentan como dos subsistemas ${ }^{51}$, como dos masas conmensurables, en interdependencia mutua. Estos dos subsistemas, que, como vimos en el comienzo de esa obra, tienen un carácter de representación (vid. supra, nota 40), aparecen como dotados de cualidades desemejantes ${ }^{52}$. Y, sin embargo, por razón de su capacidad de objetivación, en el contexto de un universo de mercancías disponibles y tendencialmente renovables, el dinero se convierte no sólo en medida, sino en mediador de las relaciones sociales, entendidas éstas como interacciones y mentalidades de los sujetos.

El dinero configura, por su estructura y sus ritmos de cambio, las mentalidades y los estilos objetivos. Éstas son las equivalencias, en las que no podemos ahora entrar, entre moneda, sistema jurídico y vida intelectual ${ }^{53}$. Pero, además, aparece la importancia radical de esta realidad y simbólica dineraria para el tránsito a una nueva forma de vida.

«La racionalidad social que sin duda interviene aquí explica por qué la riqueza moderna se mantiene hoy mucho menos tiempo en una sola familia que antes, cuando no era de naturaleza pecuniaria. El dinero busca, por así decirlo, la mano fructífera, lo que ha de ser tanto más evi-

49 G. SimMEL, Filosofía del dinero, o.c., p. 45.

${ }^{50}$ G. Simmel, Filosofia del dinero, o.c., p. 48.

51 G. SimmeL, Filosofía del dinero, o.c., p. 126.

52 "Hay menos mercacías que dinero y la proporción entre la mercancía y su precio no es igual a la que hay entre todas las mercancías y todo el dinero.» G. Simmel, Filosofía del dinero, o.c., p. 132.

53 Véase a este respecto el trabajo de Bruno THERET, «Les médiations simboliques entre economie et politique. Simmel au delà et en déça de Marx", en VV.AA., A propos de la "Philosophie de l'argent» de G. Simmel, París, L'Harmattan, 1993, pp. 189 y ss. 
dente y ha de manar de necesidades tanto más profundas cuanto que, al parecer, es posible actuar de modo más tranquilo, más seguro y pasivo en relación con la propiedad del dinero que con ninguna otra ${ }^{54}$.

Esto nos lleva a señalar, al menos, la importancia que Simmel da al concepto de estilo de vida ${ }^{55}$, es decir, en la recepción por parte de los sujetos sociales de esta cultura objetiva y de las posibilidades de crear en su interior nuevos valores y formas. Como veremos inmediatamente en la recepción benjaminiana de Simmel, esta dimensión supera la noción individualista del sujeto del consumo para entrar en la formación de constelaciones, segmentos y modos de vida en la que la recepción de las mercancías y, sobre todo, la generación de deseos y atribuciones de valor recobra su sentido sociológico pleno.

Su punto de partida es estético, el conjunto de reflexiones sobre los objetos de arte en los nuevos escenarios del mercado - la tarea del Baudelaire crítico de arte es del mismo arranque- en los que Simmel detecta un carácter genérico: la estética específicamente moderna del estilo de vida ${ }^{56}$. Lo que, en términos de su teoría de la cultura del consumo incipiente, implica que las mercancías mediadas por la mentalidad monetarista marcan un tiempo inaugural, rompedor. Ser moderno no es sólo aplaudir el progreso, sino vivir en un nuevo tiempo sin mirar atrás. Éste es el estilo que se filtra y configura las mentalidades y los caracteres.

«Esta trascendencia de las determinaciones caracteriológicas [el estilo del calculador monetarista como forma de vida], en la cual se configura la vida con independencia de las otras consecuencias que aguzan las contradicciones de la inteligencia y la economía monetaria, se puede considerar como la objetividad del estilo vital. Éste no es un rasgo que se añada a la inteligencia, sino que es su propia esencia; es la única forma accesible a los hombres a través de la cual éstos pueden conseguir una relación con las cosas que no esté alterada por la contingencia del sujeto" ${ }^{57}$.

El estilo, categoría central en las investigaciones actuales sobre el consumo, adquiere aquí por primera vez un rango propio. Es el repertorio de signos, de objetos-signo, configurador de lo objetivo y lo subjetivo y sus distorsiones y distancias. De esta potencia de troquelado se sigue el que el modelo de estilo de vida de la clase ociosa emergente se consolide poco a poco — por debajo

${ }^{54}$ G. Simmel, Filosofía del dinero, o.c., p. 351.

55 Es interesante cotejar este concepto con el weberiano de "estilización de la vida", como forma de la nueva cultura burguesa. Para una lectura sugerente en torno a este modelo, véase Carlos Soldevilla, Estilo de vida. Hacia una teoría psicosocial de la acción, Madrid, Entimema, 1998.

56 G. Simmel, «Das Problem des Styles», en Decorative Kunst, 11, 7, 1908, p. 313.

57 G. Simmel, Filosofía del dinero, prate III: "El Estilo de vida», p. 544. 
incluso de las afirmaciones del ahorro y del gasto productivo que el sistema hace- como modelo. Estilo es la elevación a un tipo imitable de las relaciones sociales concretas en el intercambio burgués monetarista como modelo hegemónico. Por ello, el análisis del consumo va a quedar aquí dotado de un concepto fundamental: el predominio del grupo de pertenencia y de referencia, frente a la mera consideración individual, como formas explicativas del consumo real.

«Mientras las modas - y no se trata aquí sólo de modas en la vestimenta- duraban aún cierto tiempo y mantenían cohesionados círculos relativamente reducidos, podía darse, por así decirlo, una relación personal entre el sujeto y los contenidos singulares de aquélla... [el cambio hoy radica en] la multiplicidad de estilos que nos encontramos en los objetos de la vida cotidiana, desde la arquitectura de las viviendas a la impresión de los libros, desde las esculturas a los jardines, y la decoración de habitaciones en las que se acumulan al mismo tiempo el Renacimiento y el orientalismo, el barroco y el estilo imperio, el prerrafaelismo y la regularidad del realismo" ${ }^{58}$.

\section{LA MODA, EL TIEMPO, EL PROGRESO}

Si en los trabajos en torno al dinero Simmel traza la dimensión básica de la cultura del consumo en sus espacios de relación, su aportación se radicaliza y hace más depurada en los trabajos en los que enfoca directamente la cuestión del tiempo. Es decir, la capacidad de las mercancías, como grandes mediadores de toda relación social, para inventar un nuevo tiempo, tanto en el orden de la representación como en el de la vivencia. Y en este caso no se trata de una metáfora, sino de una ruptura en el orden de lo real.

Me limitaré a presentar algunos fragmentos de su trabajo sobre la moda, como emblema de una serie de ensayos en los que, como dice Lukács en la semblanza mencionada, demuestra «su capacidad para ver tan agudamente el fenómeno más pequeño y más inesencial de la vida diaria sub specie philosophiae que aquél se vuelve transparente y por su transparencia resulta perceptible una eterna coherencia formal de significado filosófico ${ }^{59}$.

«La prueba más clara de que la moda es un mero engendro de necesidades sociales, mejor aún, de necesidades psicológicas puramente formales, está en que casi nunca podemos descubrir una razón material, estética o de otra índole, que explique sus creaciones. Así, por ejemplo, prácticamente se hallan nuestros trajes, en general, adaptados a nuestras necesi-

58 G. Simmel, Filosofia del dinero, o.c., pp. 581-582.

59 G. LUKÁCS, «Georg Simmel», en D. Frisby (ed.), o.c., 1994, vol. I, p. 98. 
dades; pero no es posible hallar la menor huella de utilidad en las decisiones con que la moda interviene para darles tal o cual forma: levitas anchas o angostas, peinados agudos o amplios, corbatas negras o multicolores. A veces son de moda cosas tan feas y repelentes, que no parece sino que la moda quisiese hacer gala de su poder mostrando cómo, en su servicio, estamos dispuestos a aceptar lo más horripilante. Precisamente, la arbitrariedad con que una vez ordena lo que es útil, otra lo incomprensible, otra lo estética o prácticamente inocuo, revela su perfecta indiferencia hacia las normas prácticas, racionales de la vida. Con lo cual nos transfiere a la única clase de motivaciones que restan, excluidas las antedichas, a saber: las típicamente sociales ${ }^{60}$.

Esta entrada en materia supone una mayor depuración respecto de trabajos anteriores en el modo de enfocar el consumo. El sentido de este universo de objetos y sujetos no es la compra, con su secuela que es la satisfacción de necesidades. Pero tampoco es el sostenimiento de la dinámica del deseo, incolmable, de objeto en objeto. El sentido profundo de este nuevo cosmos de la moda, de los objetos y estilos de vida que la moda trae, es la reproducción del sistema social. De sus jerarquías, de sus segmentaciones, de sus identidades. Se trata, en segundo lugar, de una modificación del tiempo vivido y, a través de él, del tiempo del progreso.

«El predominio que la moda adquiere en la cultura actual — penetrando en territorios hasta ahora intactos, y en los ya poseídos intensificándose, es decir, intensificando el tempo de su variación- es puramente concreción de un rasgo psicológico propio a nuestra edad. Nuestra rítmica interna exige que el cambio de las impresiones se verifique en períodos cada vez más cortos. $\mathrm{O}$, dicho de otro modo: el acento de cada estímulo o placer se transfiere de su centro sustancial a su comienzo o su término. Comienza esto a vislumbrarse en los síntomas más nimios; por ejemplo, en la sustitución, cada vez más generalizada, de los cigarros por los cigarrillos; se revela en la manía de viajar que sacude la vida del año en el mayor número posible de períodos breves, con la acentuación de las despedidas y los recibimientos. Es específico de la vida moderna un tempo impaciente, el cual indica, no sólo el ansia de rápida mutación en los contenidos cualitativos de la vida, sino el vigor cobrado por el atractivo formal de cuanto es límite, del comienzo y del fin, de llegar y del irse. El caso más compendioso de este linaje es la moda, que, por su juego entre la tendencia a una expansión total y el aniquilamiento de su propio sentido que esta expansión acarrea, adquiere el atractivo peculiar de los límites y extremos, el atractivo de un comienzo y un fin simultáneos, de la novedad y, al mismo tiempo, de la caducidad.»

${ }^{60}$ G. Simmel, Filosofia de la moda, en Cultura femenina y otros ensayos, trad. de E. Imaz, J.-R. Pérez Bances, M. G. ${ }^{a}$ Morente y F. Vela, Ed. Austral, 1938. 
Dimensión ínsita en los objetos de moda y, sobre todo, en el sistema de representaciones que ésta — como el dinero- genera. Se trata de una operación de la cultura; inculca, por la vía de los objetos de uso y de cambio, una idea metafísica: cómo pensar lo que estamos viviendo, a saber, que renovarse es morir. O, lo que es lo mismo, entrar en la dinámica de la muerte moral de los objetos, condición de su eterna aparición, continua novedad. De ahí la dramática vivencia del presente.

«Su cuestión no es "ser o no ser", sino que es ella a un tiempo ser y no ser, está siempre en la divisoria de las aguas que van a lo pasado y a lo futuro, y, merced a ello, nos proporciona durante su vigencia una sensación de actualidad más fuerte que casi todas las demás cosas.»

Esta ambivalencia desemboca en la generalización que Simmel hace del fenómeno de la moda. Lo realmente importante es que crea un nuevo tiempo social. La moda inventa el instante.

"Aun cuando la culminación momentánea de la conciencia social en el punto que la moda designa, arrastra consigo el germen mortal de ésta, su destino de desaparecer, no la descalifica en conjunto tal caducidad, antes bien, agrega a sus encantos uno más. Al menos no queda degradado un objeto porque se le califique como "cosa de moda" más que cuando se le aborrece por otras razones de fondo y se le quiere despreciar; en este caso, ciertamente la moda se vuelve concepto de valor y toma una significación peyorativa. Por lo demás, cualquiera otra cosa igualmente nueva y que se extienda súbitamente sobre los usos de la vida no será considerada como moda si se cree en su persistencia y sustantiva justificación. Sólo la llamará así quien esté convencido de que su desaparición será tan rápida como lo fue su advenimiento. Por esto, entre las causas del prodominio enorme que hoy goza la moda, es una creciente pérdida de fuerza que han experimentado las grandes convicciones, duraderas e incuestionables. Queda el campo libre para los elementos tornadizos y fugaces de la vida. El rompimiento con el pasado en que la humanidad civilizada se ocupa sin descanso desde hace un siglo, aguza más y más nuestra conciencia para la actualidad. Esta acentuación del presente es, sin duda, una simultánea acentuación de lo variable, del cambio, y en la misma medida en que una clase es portadora de la susodicha tendencia cultural, se entregará a la moda en todos los órdenes, no sólo en la vestimenta.»

Esta revolucionaria mirada pide aún muchas reflexiones. Por dar un incitante ejemplo de ellas, concluyo con la fecunda recepción del Simmel generalista - como dice Alfonso Ortí, para el sociólogo- de lo concreto en uno de los analistas de la socidad de consumo en la siguiente generación, el período de entreguerras, Walter Benjamin. 


\section{SIMMEL EN LOS PASAJES BENJAMINIANOS}

Una de las recepciones más fecundas de la mirada simmeliana sobre el universo del consumo, formado por un sinfín de señales que aún no están trabadas y, sin embargo, ofrecen pautas de identificación, es la que Walter Benjamin hace en su Passagen Werk, el Libro de los Pasajes. En él, como es sabido, recoge y construye el más amplio, riguroso y apasionado acopio de materiales para tratar de explicar, como Simmel ha venido haciendo, la gran mutación silenciosa y, sin embargo, espectacular: el advenimiento de la sociedad de consumo. Benjamin toma como corpus y motivo para componer su gran alegoría el París del XIX, el de las barricadas comuneras y el de la perforación fantasmagórica de las calles de siempre en la forma de los pasajes comerciales. Simmel ha tomado, como es sabido, referentes de lo inmediato — de su condición berlinesa, la misma que Benjamin si éste no hubiera sido tan nómada- para estilizarlos en caracterizaciones y diagnósticos valederos para la universalidad del proceso de industrialización en general ${ }^{61}$.

Cuatro son los principales ejes temáticos del texto benjaminiano en el que recoge e integra sugerencias de Simmel sobre el mundo del consumo conspicuo que surge en la metrópolis que experimentan la mayor transformación. La noción de cultura y el modelo que Simmel aplica a su análisis de los nuevos escenarios mediados por el dinero y la lógica de la mercancía. Las figuras de nueva identidad: el flâneur y los espacios urbanos. La importancia de los objetos. La importancia del estilo y de la moda. Concluiré, pues, con la presentación de estos fragmentos que no tienen aún versión en español, tomando como referencia los textos de las obras completas (vol. V) y la versión francesa que, con textos originales de Benjamin en francés, se editó bajo el nombre de Paris, capitale du XIX siècle.

En la percepción de la cultura, que es el caso de la vinculación con Simmel, Benjamin no oculta la fascinación que las sugerencias simmelianas le aportan, así como el papel de constructor de teoría que aquél transmitió a sus discípulos más directos y amigos de Benjamin, como Bloch, Kracauer y, en un trasfondo peculiar, el mencionado Lukács. La estrategia de Benjamin en el Passagen-Werk incluye un enorme rigor en la construcción metodológica y una dispersión, un verdadero estado de atención flotante, en el acopio de materiales.

La construcción metodológica arranca de una consideración de la cultura que se inserta en el linaje del materialismo histórico, aunque, como Benjamin apunta, sin el peso de la noción de progreso: se puede considerar — dice Benjamin del conjunto de su obra sobre el consumo- que uno de los objetivos

${ }^{61}$ Esta dualidad es la que aparece en algunos de los trabajos más recientes, como los de Felicitas Dörr-Backes y Ludwig Nieder (eds.), Georg Simmel zwischen Moderne und Postmoderne, Würzburg, Königshausen \& Neumann, 1995; Patrick WATIER, Georg Simmel: la sociologie et l'expérience du monde moderne, París, Méridiens/Klincksieck, 1986; Heinz-Jürgen Dahme y Otthein Rammstedt (eds.), Georg Simmel und die Moderne: neue Interpretationen und Materialien, Frankfurt am Main, Suhrkamp, 1984. 
metodológicos de este trabajo es hacer la demostración de un materialismo histórico "que ha aniquilado en sí la idea de progreso. En esto el materialismo histórico tiene toda la razón al distinguirse de los hábitos de pensamiento burgueses. Su concepto fundamental no es el progreso sino la actualización ${ }^{62}$. Idea ésta de la actualización muy simmeliana, en el sentido ya indicado de la detección de la fractura del largo tiempo histórico y la atención a la apertura del presente. Éste es el mundo de la cultura de las mercancías.

Pero la noción de cultura y su abordaje implica, en el caso de Benjamin, insertar la mira de Simmel sobre los procesos de objetivación de las subjetividades en el encuadre de una estrategia iniciada por Marx. Y aquí podemos decir que si bien Simmel trabaja con el bastidor de la lógica de la mercancía como gran ahormante de la cultura del capitalismo de consumo incipiente y lo hace con categorías de la filosofía crítica, Benjamin incorpora además una atención a las formas de la cultura en lo que éstas tienen de jeroglíficos. Este término - que es una palabra testigo del Marx del fetichismo de la mercancía y también de Freud- implica un programa de análisis de las formas de cultura del consumo en la medida en que éstas adoptan el aspecto de la distorsión, la apariencia cifrada. Por eso interesa la reconstrucción de la fantasmagoría, de lo no sabido, de lo inconsciente, el trabajo del sueño presente en los espacios de la vida de las ciudades. Esta perspectiva, muy marxiana y freudiana ${ }^{63}$ al tiempo, es la que comparten Benjamin y Kracauer, recibiendo y potenciando la aportación de Simmel en la comprensión de los fenómenos del margen, de lo que antes llamamos la cara oculta del consumo. Es lo que Remo Bodei destaca, al nombrar la crítica de la cultura del consumo como una experiencia de las formas $^{64}$. Siguiendo el ensayo de Kracauer Das Ornament der Masse ${ }^{65}$, es posible aquilatar, muestra Bodei, el nexo entre Simmel y Benjamin cuando ambos, más allá de las autodefiniciones de los sujetos de una sociedad dada, muestran su atención a la cultura no consciente. Kracauer dice que «las manifestaciones de la superficie, en la medida en que no están iluminadas por la conciencia, nos garantizan un acceso inmediato al contenido de lo existente, a cuyo conocimiento está ligada - y viceversa - la interpretación. El contenido fundamental de una época y sus mociones (Regungen) inobservadas se esclarecen recíprocamente».

Aquí se puede ver más claramente, por tanto, la conveniencia de un método diverso que supera o desplaza las categorías simmelianas de la dialéctica objetivación-subjetivación. Se trata de la incorporación al análisis sociológico de las categorías de lo inconsciente, entendido esto no como un lugar solipsis-

62 W. Benjamin, Passagen Werk [N 2, 2].

${ }^{63}$ Estas bases las desarrollo en mi trabajo actual La fábula del bazar. Los orígenes de la cultura del consumo, confío en que de próxima aparición. Antecedentes son los artículos (Balsa y Revista de Occidente).

${ }^{64}$ Remo BodeI, «L'expérience et les formes. Le Paris de W. Benjamin et de S. Kracauer», en H. Wismann (ed.), Benjamin et Paris, París, Ed. Du Cerf, 1986, pp. 33 y ss.

65 S. Kracauer, Das Ornament der Masse, Frankfort, Suhrkamp, 1977, p. 50. 
ta, arcano e inefable, sino - muy en consonancia con la mirada del Freud analista de esta misma crisis de la cultura- disperso entre las señales y los objetos de las nuevas ciudades y de los nuevos espacios del mercado. La intuición simmeliana de que lo contenido o depositado en los objetos habla más de nuestra cultura tecnocéntrica que los contenidos supuestamente conceptuales de la misma, es continuada aquí por el acopio de señales que representan las miles de citas y notas acerca de los pasajes del comercio. Por ello, el llamado impresionismo de Simmel, la yuxtaposición de estampas trabajadas cada una de ellas como si fuese el único objeto de indagación, adquiere en Benjamin el carácter de una disposición premeditada. La dispersión en el acopio de materiales tiene que ver con la técnica del montaje que produce nuevos efectos y hallazgos teóricos (recibida del surrealismo) y los procesos de interpretación no siguen una lógica lineal, sino, por el contrario, se atreven a incursionar de manera decidida en los procedimientos de la metáfora y de la alegoría como modo de conocimiento. Crear modelos alegóricos o metafóricos sería el método coherente con un repertorio de objetos y de signos que no se dejan reducir a la lógica de la utilidad y de la identidad. El montaje, y no el tratado, compone un discurso crítico que pretende acercarse a los contenidos de las exposiciones universales, los escaparates de los pasajes y los mundos de la vida de las ciudades de consumo. Y éstos no son lineales, son versátiles y engañosos como una fantasmagoría. Captar así lo peculiar de la cultura del consumo es hallazgo de Simmel, y su despliegue incorporando otras miradas convergentes es mérito de la tenacidad de Benjamin.

La cultura del consumo tiene, pues, un calado y una difusión que la tarea simmeliana desbrozaron en sus ejes fundamentales. Veamos la recepción benjaminiana de éstos y los desplazamientos a los que son sometidos en el itinerario de los pasajes.

En el principio sigue estando Goethe. En la estrategia expositiva de Benjamin, que llega a tender nexos entre su trabajo sobre el drama barroco como un antecedente del trabajo de análisis del jeroglífico del consumo, aparece el magisterio de Simmel como receptor del concepto de verdad goethiano, y no sólo como receptor, sino como aplicador fecundo del mismo al análisis de la sociedad industrial y sus tensiones. En el Passagen Werk, después de esbozar una importantísima conceptualización de uno de los núcleos de la nueva cultura - la imagen [N 2a, 3]—, explicita su herencia simmeliana. En la metódica elegida, no se puede decir que el pasado ilumina el presente o que el presente ilumina el pasado. "Una imagen, es el lugar en el que el Antaño se encuentra con el Ahora en un destello que forma una constelación... La imagen es la dialéctica detenida.» El siguiente fragmento -y éste es uno de los efectos que produce en su riqueza de sentidos — da el salto a la verdad goethiana:

"Al estudiar la presentación por Simmel del concepto de verdad en Goethe, me ha parecido muy claro que mi concepto de origen en el libro sobre el drama barroco es una transposición rigurosa y concluyente del 
concepto goethiano de dominio de la naturaleza en el domino de la historia. El origen es el concepto de fenómeno originario desligado del contexto pagano de la naturaleza e introducido en los contextos judíos de la historia. De este modo emprendo yo en el trabajo de los pasajes un estudio sobre el origen. Realmente me aplico a encontrar el origen de las formas y de las transformaciones de los pasajes parisinos, de su nacimiento a su final, y lo encuentro en los hechos económicos. Estos hechos considerados desde el punto de vista de la causalidad, es decir como causas, no serían fenómenos originarios; no lo llegan a ser más que cuando aparece en su propio desarrollo - despliegue, sería un término más apropiado- la serie de las formas históricas concretas de los pasajes, como la hoja al abrirse revela toda la riqueza del mundo empírico de las plantas» [N 2a, 4].

La cultura del consumo incipiente tiene una densidad exuberante que no es posible reducir a un nexo causal ni siquiera desde el materialismo histórico. Y aquí vemos un sentido más preciso del término actualización y expresión, de raigambre simmeliana: los fenómenos de la cultura del consumo, aunque remiten a una mutación estructural en lo económico (el paso del capitalismo de producción al de consumo), establecen su propio origen en su despliegue. El origen sólo es legible a posteriori ${ }^{66}$.

La cuestión de las identidades que el consumo trae cristaliza en el análisis de las nuevas figuras metropolitanas. No sólo los productores o los consumidores, en sus modos primeros que apenas inician la pauta del consumo no productivo, sino aquellos nuevos que muestran en sí los efectos, los costes no previstos de la modernización. La prostituta, el vagabundo, el que recoge las basuras - emblema de lo improductivo, del despilfarro, en la gran urbe-, el flâneur. Todos ellos son el sorprendente objeto de la reflexión de Benjamin, que sigue en esto la mirada atenta a los márgenes que Simmel pone en marcha con sus trabajos sobre el secreto y el extranjero y, especialmente, el capítulo V de la Filosofía del dinero, en el que trata del equivalente monetario de los valores personales: la fenomenología de la prostitución contemporánea es un antecedente claro de las apreciaciones de Benjamin. Estos nuevos tipos sociales no son caso típico, son la muestra de la operación de fondo que se está obrando en la vieja estructura de clases de la industrialización. En la saga de Baudelaire y Poe aparece este modo de análisis más riguroso, más atento a lo peculiar, que desborda las categorías, sobre la forma de estructurarse la nueva sociedad de la abundancia ofrecida como espectáculo.

Benjamin establece un marco de reflexión a partir de la dialéctica de la cultura. Precisamente tomando apoyo en la Filosofía del dinero, en la que Simmel

${ }^{66}$ Una brillante aplicación de esta idea a la crítica de la cultura en la sociedad del consumo de masas es el libro de Nelly Schnaith, La invención del origen, Barcelona, Café Central, 1992, así como su reciente Paradojas de la Representación, Barcelona, de la misma editorial, 1999. 
presenta la fuerza del ideal cultural como un atractor que unifica los planos estético, científico y moral. El vector de la cultura, que subraya la cita comentada de Benjamin, es el que constituye con sus piedras sillares — la metáfora es de Simmel-, la superación del ser humano de su estadio de naturaleza ${ }^{67}$. Esta unificación que supera las esferas del idealismo clásico se encuentra en la sociedad del protoconsumo con su piedra de toque en la medida en que las identidades que produce, construidas aparentemente en la lógica del progreso, son su negación o, al menos, su conversión en paradoja.

El consumo presentido como opulencia que esconde la lógica de la mercancía y la mercantilización de las relaciones entre los nuevos urbanitas albergaba la promesa de la superación, si no de un estadio de naturaleza, al menos de un atemperamiento de las desigualdades ancestrales. Estas imágenes de los nuevos oficios del desgaste y el despilfarro, que hacen como que miman el tiempo del trabajo y lo suspenden en una espectacular marginación, son, como Susan Buck-Morss recoge, verdaderas imágenes dialécticas ${ }^{68}$ que ayudan a pensar la irritante tensión de los nuevos mundos de la vida cotidiana. Entre la superación del idealismo al que Simmel alude y la estigmatización moralizante, rechazable por el investigador social, Benjamin entiende que su mirada debe ser precisa, no declarar ninguna época como de decadencia $[N 1,6]$, ni tampoco tacharla desde la beata óptica del progreso productivista.

Benjamin dedica a la prostitución y al juego — nuevos fenómenos de cultura del comercio de los pasajes - todo un apartado, el O, de su obra. En él no aparecen referencias explícitas a Simmel, pero sí existe una perspectiva que comparte con el analista de la equivalencia del dinero: el desplazamiento del análisis de las formas llamadas patológicas hacia las formas sancionadas como normales o valiosas. Dice Simmel:

«También en el caso de la prostitución puede apreciarse el fenómeno de que, por encima de una cierta cantidad, el dinero pierde su falta de dignidad y su incapacidad para compensar valores individuales. El horror que la "buena" sociedad moderna profesa ante la prostituta es tanto más pronunciado cuanto más miserable e infeliz es ésta y se va dulcificando a medida que sube el precio de la venta, hasta llegar a recibir en sus salones a la actriz de la que todo el mundo sabe que es una mantenida de un millonario, aunque esta mujer puede ser más interesada, más falsa y más depravada en su interior que la prostituta callejera» ${ }^{69}$.

Benjamin no presenta este tono moralista en medio de la disección que, por lo demás, es certera en el caso de Simmel. Éste sitúa el fenómeno de la

67 W. Benjamin, Das Passagen -Werk [N 14, 3].

${ }^{68}$ Susan BucK-MorsS, «La Flâneur, l'Homme-sandwich et la Prostituée: Politique de la Flânerie», en H. Wissman (ed.), Walter Benjamin et Paris, París, Ed. Du Cerf, 1986, pp. 366-367.

${ }_{69}$ G. Simmel, Filosofía del dinero, o.c., pp. 477-478. 
prostitución en los marcos institucionales, que incluyen el matrimonio en sus formas más recientes. Como ocurre con Veblen respecto de las figuras de «la edad de la inocencia» norteamericana, el objetivo es mostrar el lugar del intercambio - incluido el dinerario- en las relaciones sociales conspicuas, es decir, visibles como modelo. Benjamin da por sentada esta tarea y desplaza la descripción analítica a los nuevos espacios urbanos de los pasajes. Su tono es deliberadamente alegórico. La prostitución impregnada del ritmo del pasaje comercial es un emblema de la nueva dependencia del mercado. Así comienza su retrato de situación de los pasajes comerciales, en los que prostitución y juego se funden:

"¿Sus vagabundas infatigables no le han acostumbrado a él a dar en cada lugar una nueva interpretación de la imagen de la ciudad? Acaso él no transforma el pasaje en un casino, en una sala de juegos donde pone en sus fichas rojas, azules, amarillas, sus sentimientos acerca de las mujeres, un rostro que aparece — ¿responderá a su mirada? - acerca de una boca muda — ¿hablará ella?- - Lo que, disimulado en cada uno de los números del tapete verde, el jugador contempla, es decir la dicha, le lanza aquí un guiño en medio de todos los cuerpos femeninos, haciéndole entrever lo que es la quimera de la sexualidad: su tipo de mujer. Éste no es otra cosa que el número, la cifra sobre la que la felicidad va a ser en ese instante llamada por su nombre, para saltar inmediatamente después en otro número» ${ }^{70}$.

La cifra y el número vinculan estos dos fragmentos con una intención semejante: mostrar la cuantificación mercantil de las relaciones. Esto Benjamin lo aprende, sin duda, de Simmel. Pero Benjamin suspende críticamente la mirada de aquél, tal vez porque su discrepancia de fondo tiene que ver con el diferente modo de entender no tanto los nuevos escenarios del consumo cuanto el modelo de trabajo o, mejor, la interpretación del trabajo que Marx inicia. De todos modos, el Simmel a quien en un fragmento considera representante del modelo pequeño burgués - pues se empeña en espiritualizar la materia, el trabajo material, dice Benjamin [X 6, X 6a] - no está lejos, pese a la disimetría de términos con el viajero que celebra en Moscú la posibilidad revolucionaria, del intento superador de las categorías clásicas (trabajo manual/trabajo intelectual) por ser éstas reducibles a un plano moral (dice Simmel) que, a mi entender, hay que considerar como sinónimo de "productivo" o "poiético», no cosificado ${ }^{71}$ o bien superables en un nuevo modo de circulación en el mercado

70 W. Benjamin, Das Passagen Werk (O 1, 2).

${ }^{71}$ Esta visión se atribuye también a la construcción del valor de los objetos como un principio activo. Los pasajes de la Filosofía del dinero que comenta Benjamin son especialmente de la p. 522 en adelante. El carácter activo, prefigurador de todo trabajo, aparece bien aquí: "Si visto desde fuera aquel trabajo (físico) supone la superación de obstáculos, la configuración de una materia que no se somete sin más a tal forma, sino que, en principio, le ofrece resistencia, la parte interna de este trabajo muestra, también, el mismo aspecto» (ibid., pp. 527-528). 
(dice Benjamin). Si mi interpretación no es incorrecta, Simmel sigue manteniendo aquí el principio afirmativo no reactivo de la herencia nietzscheana: cualidad ésta que atribuye a toda forma de trabajo productivo, en tanto que la versión de Marx puede aparecer, según él, como reductiva al privilegiar como modelo explicativo «y moral» el trabajo manual. La corrección de Benjamin adolece también de su momento «soviético»: más que una disquisición terminológica apunta el tono metasocial, metafísico, del maestro indirecto que supone "un fondo espiritual» (a mi entender, un principio activo, no reactivo) a toda actividad productiva.

Como vemos, estas figuras atañen a un cambio radical en la percepción del trabajo, de las actividades regidas ahora por un principio suplementario en apariencia, central en realidad: la circulación espectacular en el mercado. $\mathrm{Su}$ carácter de espectáculo y de prescriptores de una forma de vida en que la exhibición de las mercancías y sus precios es la clave.

Por eso, el flâneur es un representante de la tensión paradójica del nuevo escenario: no hace nada en apariencia, pero sin él el mercado se detiene. Detecta las novedades, que tienen en él el destinatario ideal, anónimo, incesante buscador como el hombre de la multitud del relato de Poe. En la composición de Benjamin sobre esta figura, que ocupa todo el cuaderno $\mathrm{M}$, aparece el lema que Hofmannsthal pone en La puerta y la muerte ${ }^{72}$ : "leer lo que no se ha escrito nunca». Esta voluntad creadora que lleva a reconocer en un personaje nuevo, el que se pasea entre los pasajes comerciales y las avenidas en una ciudad descentrada y en un tiempo detenido, la condensación del consumo, Benjamin la recibe principalmente de Simmel. Del ensayo de éste sobre la sociología de los sentidos, selecciona esta consideración:

"QQuien ve sin oír está mucho más... inquieto que quien oye sin ver. Aquí tiene que haber un factor significativo para la sociología de la gran ciudad. Las relaciones entre los hombres de las grandes urbes... están caracterizadas por una preponderancia marcada de la actividad de la vista robre la del oído. Y esto..., ante todo a causa de los medios de comunicación públicos. Antes del desarrollo que han adquirido los ómnibus, los ferrocarriles, los tranvías del siglo XIX, la gente no tenía ocasión de poder o de deber mirarse recíprocamente durante minutos u horas seguidas sin hablar". El factor que Simmel pone en relación con el estado inquieto y lábil tiene, por lo demás, una cierta base en la fisiognomonía vulgar. Hay que estudiar la diferencia entre ésta y la del siglo XVIII» [M 8. $\left.{ }^{\mathrm{a}}, 2\right]$.

La fisiognómica o fisiognomónica, a la que se refieren buena parte de los analistas de este período, tiene que ver con la nueva configuración del sujeto, al que no hace el trabajo, sino principalmente la relación con el mercado: las masas que pululan por las ciudades, de las que el girovagante es señal y aban-

${ }^{72}$ H. von Hofmannsthal, Der Tor und der Tod, Gesammelte Werke, 1952, p. 220. 
derado. De la intuición de Simmel, centrada en el privilegio y la servidumbre del poder de lo visual en esta cultura, Benjamin hará una gran floración de determinaciones: el que recibe el espectáculo de las mercancías también toma a

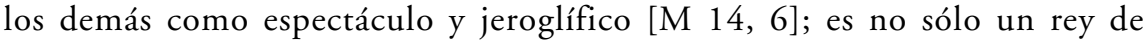
incógnito (imagen de Baudelaire), sino también un detective de las tendencias y costumbres, el primer investigador espontáneo de los modos del mercado. Y, entre otras muy perspicaces, añade Benjamin esta determinación: «La identificación con la mercancía es fundamentalmente una identificación con el valor de cambio. El flâneur es el virtuoso de esta identificación. Lleva en su paseo el concepto mismo de venalidad» [M 17a, 2].

Simmel está tras estas mismas consideraciones, como Benjamin destaca en otra cita que adopta y resume de la Filosofía del dinero: «una promiscuidad tan estrecha... como la de la cultura urbana... lleva en sí misma sus límites y reservas interiores. La monetarización de las relaciones, manifiesta o disfrazada, desliza una distancia funcional entre los hombres que es de hecho una protección interior contra esta proximidad demasiado estrecha» [M 17, 2].

El extranjero que ha producido las grandes ciudades, los procesos de exclusión de la producción y de inclusión en el espectáculo de los pasajes, es el mismo que Simmel ha dibujado con trazo preciso en su ya mencionado ensayo. Del que es otro choca precisamente que su presencia y lejanía se den a la vez $\mathrm{v}^{73}$, su estar y no ser, algo que contribuye, a mi entender, a la aplicación del concepto de aura que Benjamin utiliza en estos pasajes para explicar el fenómeno de las muchedumbres excluidas como miembros activos y recuperadas como soportes de la circulación de las mercancías: «Huella y aura. La huella es la aparición de una proximidad, por muy lejos que pueda estar lo que la causó. El aura es la aparición de lo lejano, por muy próximo que esté lo que lo evoca. Con la huella nos apropiamos de la cosa, con el aura ella es la que se adueña de nosotros» [M 16a, 4]. La distinción de conceptos, que, como es sabido, Benjamin emplea para hablar de la obra de arte en tiempos de una tecnología que la reproduce sin fin, encuentra su contexto en este fenómeno de la extranjería en la ciudad-mercado.

El hombre-sandwich, el hombre anuncio que va por las calles, es la versión explícitamente mercantilizada del flâneur [M 19, 2]. La marca es el exponente lingüístico que tiene el rango de jeroglífico como los mismos espacios urbanos a los que comienza —en fachadas y tranvías - a puntuar. Las imágenes espaciales (Raumbilder) — dice Kracauer - son los sueños de la sociedad. En la medida en que los jeroglíficos de estas imágenes pueden ser descifrados, se encuentran las bases de la realidad social ${ }^{74}$. Radical hallazgo en el que Simmel se encuentra con el modelo del fetichismo (la mercancía como jeroglífico). Lo que prueba, como dice Vidler, que las casas y las cosas del consumo son, sobre todo, signos que interpretan otros signos del consumo:

73 K. H. WolfF, The Sociology of Georg Simmel, Free Press of Glencoe, 1964, p. 407.

${ }^{4}$ Kracauer, "Ubre Arbeitsnachweise», Frankfurter Zeitung, 17 de junio de 1930, citado en A. VIDLER, o.c., p. 33. 
"Cuando Benjamin se refiere a las arcadas, o Kracauer al hall del hotel, tendemos a asociar estas formas inmediatamente como sus referentes históricos y físicos, ignorando el grado de artificio y de articulación cuidadosa que distingue el passage benjaminiano o el lobby de Kracauer de cualquiera de los que nosotros hayamos conocido. En un sentido real éstos son espacios puramente textuales, diseñados, si así podemos decirlo, por sus autores; ellos poseen una arquitectónica propia, particular en su status ambiguo entre lo textual y lo social; son edificios que sirven como instrumentos analíticos» $»^{75}$.

De aquí surge una nueva relación con las cosas, con los objetos en exhibición y venta. Por primera vez hay escaparates, por primera vez hay precios en las etiquetas de las mercancías. Y esta característica de los objetos de aparecer vinculados explícitamente a su cualidad de circular en el mercado es central en la mirada que Benjamin capta en el trabajo de Simmel. Cuando revisa la teoría de la mercancía de Marx, Benjamin repasa, como hemos indicado, la teoría del trabajo y de la mercancía de Simmel. Pero recoge algo más: la atención a cómo disminuye el carácter individual, peculiar en el mercado moderno. En el fragmento $[\mathrm{X} 7,1]$ rescata el pasaje de la Filosofía del dinero en el que Simmel nombra el ejemplo de la predominancia del precio como emblema de la mercancía: el bazar de cincuenta pfenning - precursor en la primera década del siglo de nuestros «todo a cien"- presenta una relación con las cosas en la que la cantidad y el precio bajo son el filtro nivelador de las demás consideraciones de preferencia o deseo.

Simmel da abundantes indicaciones en sus obras - concretamente en los mencionados artículos sobre el adorno o la coquetería, en los relativos a la moda o en la reflexión sobre el dinero- acerca de la nueva relación con los objetos que el mercado contemporáneo acarrea e impone. Benjamin incorpora su reflexión de la Filosofía del dinero (en el capítulo sobre el estilo de vida) en la que destaca la mayor duración de los objetos del Antiguo Régimen y la mayor vinculación de las personalidades con los objetos de su entorno. Ahora hay una enorme variedad que impide este vínculo con objetos singulares (las señoras se quejan de que mantener las cosas de casa «exige de ellas un servicio fetichista»). Pero también hay un ritmo de reposición más acelerado («la diferencia en el orden de la sucesión lleva al mismo resultado que en el orden de la contigüidad»: "el cambio de moda interrumpe el proceso de arraigo entre el sujeto y el objeto»). Y, en tercer lugar, no hay que dejar de lado «la pluralidad de estilos que nos ofrecen los objetos visibles cotidianos» [I 7a, 2].

El punto de vista es el de un hombre con sensibilidad ante el mundo de los objetos de arte. Coleccionista, como el mismo Benjamin, cultivador de una pasión escópica, hasta el punto de ser éste el rasgo con el que Weber le recuerda gráficamente: "Ayer estuvo Simmel en la sala Beethoven de la Filarmónica;

A. VidLER, o.c., p. 39. 
la música le hacía espirales por el cuerpo. Es muy musical, y también su sentido de los colores está muy desarrollado. Su colección de jarrones chinos monocromos es digna de ser vista ${ }^{76}$. Objetos en serie, objetos en secuencia de moda, objetos en estilos cada vez más diversificados son otros tantos modos de marcar la diferenciación precisamente en virtud del mundo de las cosas del consumo. Precisamente porque éstas en el trato que imponen a los sujetos (con ellas y entre sí) destilan su tiranía o su poder de modelado. Ya lo dejó anunciado en su reflexión sobre el dinero al hablar de la relación moderna con los objetos:

«La posesión de un objeto especialmente caracterizado, que pretende trascender aquel concepto abstracto de la propiedad, no es algo que se pueda atribuir a una personalidad sin más y desde fuera, sino que, más bien, consiste en una reciprocidad entre las fuerzas y las cualidades del sujeto y las del objeto, y esta reciprocidad únicamente puede darse en el caso de una relación especial de ambos, esto es, con una cualificación determinada del sujeto. El reverso de esta reflexión es que la influencia de lo poseído sobre el poseedor determina a éste» ${ }^{77}$.

La relación que se establece, primero en las capas superiores, en la burguesía ascendente que adopta el imaginario de la nobleza ida, luego en el espectáculo de los salones que son las calles y los comercios, es una implantación de estilo. Y éste es el cuarto concepto que deja huella en Benjamin.

La enorme perspicacia simmeliana encuentra su réplica en el amplio trabajo que Benjamin dedica a la moda, entendida ésta como analizador principal de la cultura del consumo como fenómeno social total. La sección B de los Pasajes está dedicada a los miles de aspectos de la moda fin de siglo, y en ella ocupa un lugar privilegiado la referencia a la Filosofische Kultur de Simmel, publicada en 1911, aunque incluye artículos —el dedicado a la moda es de $1905^{78}$ - anteriores. Moda y estilo se refieren entre sí como complementarios. «No hay artículo alguno que se ponga de moda: se crean artículos para que estén a la moda", es el lema que Benjamin medita [B 7,7] asombrado por el amplio espectro de sentidos que en Simmel adquieren los conceptos. Este enunciado implica la actual prefiguración de la sociedad de consumo, en la que la misma producción se ve afectada por el proceso de comunicación y recepción ${ }^{79}$. Las técnicas que acompañan la distribución y el consumo no vienen luego, al apoyo de un producto ya terminado, sino que preceden la mera producción, orientándola en el sentido del estilo de vida de los consumidores.

${ }^{76}$ Carta a Marianne Weber de primeros de 1911, en Marianne Weber, Max Weber. Biografia, Valencia, Ed. Alfons el Magnànim, 1995, p. 685.

77 G. Simmel, Filosofía del dinero, o.c., p. 368.

${ }^{78}$ La más reciente versión castellana de Cultura Femenina y otros ensayos, Barcelona, Alba, 1999, incluye este artículo sobre la moda.

79 Ver Cristina Santamarina, «Las palabras del mercado», Revista de Occidente, núm. 162, noviembre 1994, pp. 150 y ss. 
El estilo que implica segmentación es una categoría que aparece vinculada, como hemos visto, a la de clase social. Se superponen pero no coinciden biunívocamente. Hay estilos y modas que refuerzan y expresan la división de clases, pero antes hay una gran atención a la función compensatoria de la moda como creadora de estilos. La exclusión tiene que ver directamente con el género. Simmel —recogido parcialmente por Benjamin en [B 7, 8] — afirma:

"Que la moda exprese y acentúe simultáneamente el impulso hacia la igualdad y el impulso hacia la individuación, el deseo de imitación y de distinción, explica quizá por qué en general las mujeres dependen tanto de la moda. Por la debilidad de su posición social, a la que las mujeres han estado condenadas la mayor parte de la historia, se explica su relación con las "costumbres", las "convenciones" y el modo de vida universalmente aceptado y válido. El débil evita la individualización, la acción práctica con sus responsabilidades y su necesidad de defenderse con sus propias fuerzas ${ }^{80}$.

Que no se habla sólo de moda y de mujeres es evidente en el propio texto y en la recepción benjaminiana. Lo que se está formulando por vez primera es la importancia del estilo como espacio en el que se elaboran los nuevos conflictos de pertenencia y exclusión. Esto es lo verdaderamente potente del hallazgo de Simmel y de la punta que Benjamin saca. Estilo, como antes indicamos, es una categoría en la que la cultura del consumo expresa y consolida su poder de domesticación y al tiempo — no seríamos nada simmelianos sin este añadidoexpresa el poder de elaborar, de crear sentidos que puedan superar el conflicto. "Estilización de la vida» como actividad es el término más weberiano de una actividad que destaca primero Simmel. Le compete a quien está excluido: primero a la burguesía amenazada, luego a las multitudes separadas de la apropiación prometida y, ante todo y de modo constante, a las mujeres, cuya exclusión es mayor y recorre signos aparentemente integradores.

El recorrido que Simmel emprendiera en su trabajo temprano sobre el papel del dinero en las relaciones sexuales ${ }^{81}$ puso las primeras bases de la iluminación sobre el papel segmentador, más allá de las declaraciones ideológicas expresas, que los modos de la cultura del consumo ejercen sobre los grupos y las identidades sociales. Pero esta idea, la de la ideología disuelta en las cosas del consumo cotidiano, encontrará sus formulaciones más precisas en el contexto de la pauta del consumo de masas. Barthes y su aproximación a las mitologías del consumo cotidiano - que darán como fruto el excelente análisis del Sistema de la moda como constatación del poder segmentador de los signos y del lenguaje- será uno de sus principales testigos.

G. Simmel, Cultura Femenina y otros ensayos, o.c., pp. 54-55.

${ }^{81}$ "Die Rolle des Geldes in den Beziehungen der Geschlechter. Fragment aus einer "Philosophie des Geldes"» (1898), en G. Simmel, Shriften zur Philosophie und Soziologie der Geschlechter (ed. de H. Dahme y K. Köhnke), Frankfurt am Main, Suhrkamp, 1985, pp. 139-156. 


\begin{abstract}
This paper, belonging to a series of texts about the origins of the culture of the consumption, in the first 90's, offers a lecture of simmelian texts concerning the social identity's constitution following not the production's paradigm, but its relationship with the objects and processes of consumption. Before the pattern of masses' consumption a new cultural mode appears based on luxury and its conspicuous character (Veblen) and, widelier, on the mediation of commodities and its logic (fetichism) as shapers of social subjects. The critical and creative elements that Simmel builds will be fondamental in authors like Kracauer and mainly Walter Benjamin. The second part of this paper focuses on these inheritance to analyze the Benjaminian Passagen Werk.
\end{abstract}

